DEDALUS - Acervo - IGC

NOVOS DIAGRAMAS PARA A DETERMINAÇAO

DE GRANADAS

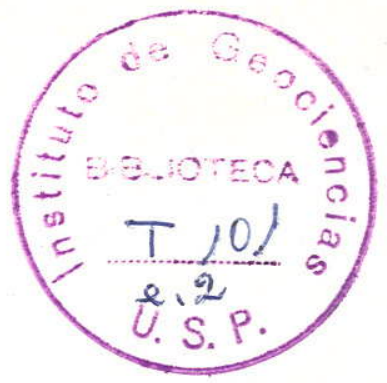

J. B. MADUREIRA FILHO

INDICE

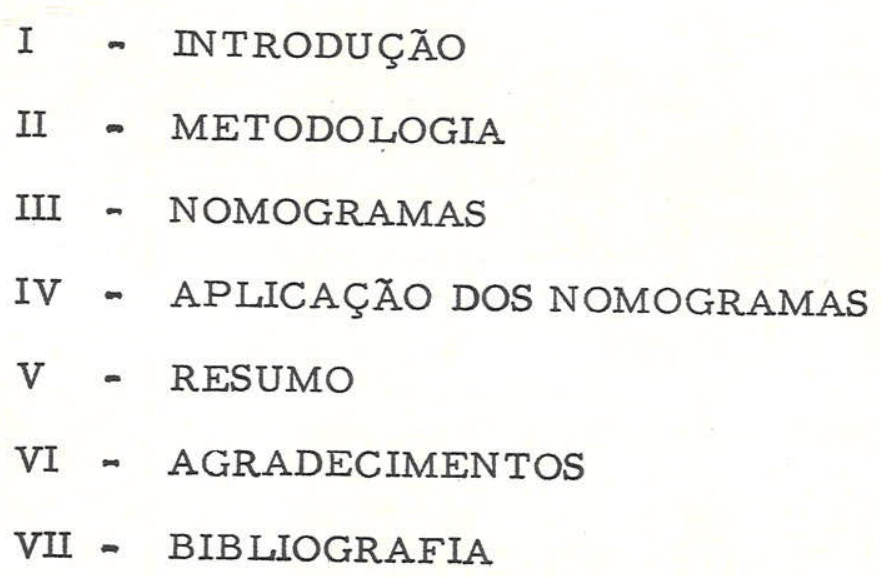

Memoria de Mestrado apresentada ao Instituto de Geociências da Univer sidade de São Paulo. 
NOVOS DIAGRAMAS PARA A DETERMINAÇAO FISICA DE GRANADAS

J. B. MADUREIRA FILHO

I - INTRODUCAO

Os têrmos isomorfos das granadas constituem minerais de determinação relativamente difícil através de suas propriedades físicas, exigindo para sua caracterização dentro do grupo, mesmo aproximada, no mínimo, três constantes físi cas: a $a_{0}$ (parâmetro da cela unitária), n (índice de refração) e D (densidade). Com frequência, entretanto, mesmo essas três constantes mencionadas se mostram insuficientes, conduzindo a resultados dúbios que sòmente podem ser devidamente esclarecidos por análises químicas semi-quantitativas de um 
ou outro cátion caracteristico ( $\mathrm{Fe}, \mathrm{Mn}, \mathrm{Cr}$, etc).

As granadas podem ser consideradas, dentro de certos limites, como misturas de duas ou mais espécies mine rais: almandina (Al), andradita (An), grossulária (Gr), piropo $(\mathrm{Pi})$, espessartita $(\mathrm{Sp})$, uvarovita e hidrogrossulária. Segundo Ford (1915), 17\% das granadas são representadas por misturas de duas espécies, $17 \%$ por misturas de quatro espécies ou mais e os restantes $66 \%$, que constituem a maioria, represen tam soluções sólidas de apenas três espécies. Nessas condições, a utilização de diagramas ternários em função da variação da composição química, juntamente com a variação das prom priedades físicas mencionadas $\left(a_{0}, n, D\right)$, podem conduzir a de terminação de um tipo de granada na maioria dos casos possíveis $(66 \%+17 \%=83 \%)$ pois as misturas duplas também po dem ser resolvidas pelos diagramas ternários.

Os diagramas ou nomogramas ternários existen tes na literatura (Kennedy, 1947, Sriramadas, 1957 e Winchell, 1951), são em primeiro lugar relativamente incompletos, pois a combinação matemática de 5 espécies diferentes de granadas .. em diagramas três a três, conduz a 10 gráficos possíveis, e aqueles autores apenas citam 8, não havendo ainda coincidência nos diagramas omitidos. Kennedy (1947) não cita os gráfi cos Al-An-Gr e Al-An-Pi, enquanto Sriramadas (1957) faz omissões dos sistemas Gr-Pi-Sp e An-Pi-Sp, não esclarecendo, ambos os autores, as razões das omissões.

Em segundo lugar, os diagramas acima citados 
utilizam-se de $a_{0}$, dimensão da cela unitária como um dos pa râmetros físicos, o qual sendo de determinação relativamente difícil, laboriosa e demorada, é substituida neste trabalho por um parâmetro equivalente, porém de obtenção mais rápida e cômoda.

Os nomogramas triangulares que serão apresentados incluem cinco diferentes espécies de granadas: almandina, andradita, grossulária, piropo e espessartita, desprezando-se as outras variedades mais raras na natureza (uvarovita e hidrogrossulária). As constantes físicas correspondentes às diver sas espécies de granadas, e que serviram de base para a construção dos nomogramas foram extraídas da literatura existentes (Kennedy, 1947, Winchell, 1951, Skinner, 1956, Sriramadas,1957 e Deer et. al., 1962).

\section{II - METODOLOGIA}

As constantes físicas utilizadas foram $\Delta 2 \theta$, defi nida pela diferença $[2 \theta(420)$ granada - $2 \theta$ (10īl) quartzo $]$, n e D. O emprêgo da diferença, $\Delta 2 \theta$, ao invés de a $\quad[2 \theta=$ $\left.=f\left(a_{0}\right)\right]$, apresenta várias vantagens sobre o método convencio nal.

A diferença $\Delta 20$ pode ser obtida experimentalmente em fotografias pelo método do pó (câmaras de 114,6 mm, de 57,3 $\mathrm{mm}$ ou de 28,65 mm de diâmetro) (Camargo, e Svisero, 1967), ou em gráficos registrados por difratometria. 
Em ambos os processos é necessário adicion nar à amostra pequena quantidade de quartzo (cêrca de 15\%) co mo padrão interno. O método fotográfico é especialmente ade quado para casos onde a quantidade de material é extremamente exígua (cêrca de $1 \mathrm{~mm}^{3}$ ). A exposição neste caso pode ser curm ta, pois é suficiente o registro fotográfico somente das raias mais intensas da granada e do padrão de quartzo. Na câmara de $114,6 \mathrm{~mm}$ as exposições razoáveis oscilam em torno de $30^{2}$ (anticátodo de $\mathrm{Cu}$ ) e nas câmaras de diâmetro inferiores as ex posições decrescem proporcionalmente com o quadrado dos res pectivos diâmetros, ou seja, cêrca de $8^{8}$ para $57,3 \mathrm{~mm}$ e cerm ca de $2^{2}$ para $28,65 \mathrm{~mm}$. Essas exposições podem ainda ser mais reduzidas se empregarmos regimes próximos de $1 \mathrm{~kW}=$ $=50 \mathrm{kV} \times 20 \mathrm{~mA}$ (anticátodo de $\mathrm{Cu}$ ), que embora máximos não afetam a vida do tubo, por ser aplicado durante intervalos de tempo relativamente curtos.

A difratometria, ao contrário do método fotográ fico, requer maior quantidade de material. As "corridas" podem ser apenas parciais, oscilando desde $26^{\circ}$ (para registro de $2 \theta$ Quartzo $=26,64^{\circ}$ ) àté $35^{\circ}$ (para registro de $2 \theta$ Granada $=$ $\left.34,99^{\circ}\right)$. Empregando-se velocidade de $2^{\circ}$ por minuto, o difratograma é registrado em apenas 4 ou 5 minutos, representando uma. grande vantagem em relação ao método fotográfico, o qual exige ainda as operações revelação e secagem do filme。

$$
\text { A utilização da diferença } \Delta 2 \theta \text { evita todo } 0
$$

processamento para a obtenção do parâmetro $a_{0}$, que requer no 
método fotográfico filmes completos com grande número de reflexões, e consequentemente sujeitos a longas exposições ( cerca de 24 horas ). No processo difratométrico, a "corrida" ao goniô metro deve ser a mais completa possível, desde $2^{\circ}$ a $110^{\circ}$. Além do tempo dispendido na elaboração do filme ou no preparo do difratograma, existe ainda o trabalho da leitura e cálculo dos dados A diferença $\Delta 2 \theta$ tem sido já aplicada com êxi to em outros grupos minerais, como por exemplo nas turmalinas (Camargo, 1965), e pode ser também aplicada a grupos minerais isomorfos, como olivinas, espinélios, feldspatos e epídotos.

Entretanto, para aplicação de $\Delta 2 \theta$ em lugar de a ${ }_{0}$ é necessário provar a linearidade da variação de $\quad \Delta 2 \theta$ em função da composição química o que se pode comprovar em misturas binárias, e admitindo-se como premissa verdadeira a variação linear de a o, em função da composição química, já estabelecida por Ford (1915). As tabelas 1 e 2 mostram as dife renças $\Delta 2 \theta$, para os diversos têrmos entre Piropo e Andram dita e entre Piropo e Almandina, evidenciando que existe um erro extremamente reduzido entre $\Delta 2 \theta$ (calculado) e $\Delta 2 \theta$ (in terpolado). O primeiro é obtido diretamente de $a_{0}\left(7,4546^{\circ}\right.$ para Pi 50\% - An 50\%) enquanto o segundo $\left(7,4690^{\circ}\right)$ é conseguido pela interpolação entre $8,350^{\circ} \mathrm{e} 6,558^{\circ}$, extremos da tabela, conduzin do a um erro reduzido de 0,0144.

Nessas condições os êrros mínimos constatados permitem estabelecer como linear a variação de $\Delta 2 \theta \mathrm{em}$ funm ção da composição química, permitindo considerar a diferença 
TABELA

Variação de $\quad \Delta 2 \theta$ em função da variação química entre Piropo e Andradita (CuK $\sigma_{\text {o }}$ )

\begin{tabular}{|c|c|c|c|c|c|c|c|}
\hline Piropo & Andradita & $a_{0}$ & $2 \theta(420) \mathrm{Gr}$ & $2 \theta(10 I 1) \mathrm{Qz}$ & $\Delta 2 \theta\left(\right.$ calc $\left._{0}\right)$ & $\Delta 2 \theta($ interp. $)$ & êrro \\
\hline $100 \%$ & $0 \%$ & 11,4590 & $34,9900^{\circ}$ & $26,6400^{\circ}$ & $8,3500^{\circ}$ & $8,3500^{\circ}$ & - \\
\hline $75 \%$ & $25 \%$ & 11,6063 & $34,5307^{\circ}$ & $26,6400^{\circ}$ & $7,8907^{\circ}$ & $7,9095^{\circ}$ & $-0,0188^{\circ}$ \\
\hline $50 \%$ & $50 \%$ & 11,7535 & $34,0946^{\circ}$ & $26,6400^{\circ}$ & $7,4546^{\circ}$ & $7,4690^{\circ}$ & $-0,0144^{c}$ \\
\hline $25 \%$ & $75 \%$ & 11,9007 & $33,6512^{\prime}$ & $26,6400^{\circ}$ & $7,0112^{\circ}$ & $7,0285^{\circ}$ & $-0,0173^{\circ}$ \\
\hline $0 \%$ & $100 \%$ & 12,0480 & $33,2280^{\circ}$ & $26,6400^{\circ}$ & $6,5880^{\circ}$ & $6,5880^{\circ}$ & - \\
\hline
\end{tabular}


TABELA 2

Variação de $\quad \Delta 2 \theta$ em função da variação química entre Piropo e Almandina (CuK $a_{0}$ )

\begin{tabular}{|c|c|c|c|c|c|c|c|}
\hline Piropo & Almandina & $a_{0}$ & $2 \theta(420) \mathrm{Gr}$ & $2 \theta(10101) \mathrm{Qz}$ & $\Delta 2 \theta\left(\right.$ calc $\left._{\bullet}\right)$ & $\Delta 2 \theta($ interp. $)$ & êrro \\
\hline $100 \%$ & $0 \%$ & 11,4590 & $34,9900^{\circ}$ & $26,6400^{\circ}$ & $8,3500^{\circ}$ & $8,3500^{\circ}$ & $\infty$ \\
\hline $75 \%$ & $25 \%$ & 11,4758 & $34,9360^{\circ}$ & $26,6400^{\circ}$ & $8,2960^{\circ}$ & $8,2985^{\circ}$ & $-0,0025^{\circ}$ \\
\hline $50 \%$ & $50 \%$ & 11,4925 & $34,8828^{\circ}$ & $26,6400^{\circ}$ & $8,2428^{\circ}$ & $8,2450^{\circ}$ & $-0,0022^{\circ}$ \\
\hline $25 \%$ & $75 \%$ & 11,5092 & $34,8314^{\circ}$ & $26,6400^{\circ}$ & $8,1914^{\circ}$ & $8,1925^{\circ}$ & $-0,0011^{\circ}$ \\
\hline $0 \%$ & $100 \%$ & 11,5260 & $34,7800^{\circ}$ & $26,6400^{\circ}$ & $8,1400^{\circ}$ & $8,1400^{\circ}$ & - \\
\hline
\end{tabular}


$\Delta 2 \theta$ como tão boa quanto $a_{0}$ para a construção dos nomogra mas.

III - NOMOGRAMAS

Os valores dos parâmetros unitários dos índices de refração e da densidade,foram extraídos da literatura (Deer et. al., 1962), com as correspondentes análises químicas e percentagens molares das diversas espécies, fatores indispen sáveis para a avaliação da aplicabilidade do método de trabalho proposto. Os dados necessários à elaboração dos nomogramas constam da Tabela 3.

$$
\text { O valor de } \mathrm{d}(420) \text { e do ângulo } 2 \theta \text { das gra }
$$

nadas foi calculado a partir de a pelas fórmulas.

$$
\begin{aligned}
& d^{2}=a_{0}^{2} /\left(h^{2}+k^{2}+l^{2}\right) \\
& \lambda=2 d \operatorname{sen} \theta
\end{aligned}
$$

As diferenças $\triangle 2 \theta$ deduzidas de $a_{0}$ corresm pondentes às diversas espécies do grupo das granadas estão re lacionadas na Tabela 4.

Nessas circunstâncias, por combinação três a três das cinco espécies principais de granada (almandina, andradita, grossulária, piropo e espessartita), é possível a construção de 10 nomogramas abaixo:

1. almandina - andradita - grossulária 
TABELA 3

Valôres das Propriedades Físicas (Deer et. al., 1962)

Espécie

Almandina

Andradita

Grossulária

Piropo

Espessartita

$$
a_{0}(A)
$$

11,526

12,048

11,851

11,459

11,621
$\mathrm{n}(\mathrm{Na})$

1,830

1,887

1,734

1,714

1,800
D $\mathrm{g} / \mathrm{cm}^{3}$

4,318

3,859

3, 594

3,582

4,190 
TABELA 4

Valôres de Diferença de $2 \theta$ para CuK $\propto$

\begin{tabular}{|c|c|c|c|c|c|}
\hline Espécies & $a_{0}(A)$ & $\mathrm{d}_{420}$ & $2 \theta_{420}$ & ${ }^{2 \theta_{10}} 1$ & $\Delta 2 \theta$ \\
\hline Almandina & 11,526 & 2,5772 & $34,780^{\circ}$ & $26,640^{\circ}$ & $8,140^{\circ}$ \\
\hline Andradita & 12,048 & 2,6940 & $33,228^{\circ}$ & $26,640^{\circ}$ & $6,588^{\circ}$ \\
\hline Grossulária & 11,851 & 2,6499 & $33,797^{\circ}$ & $26,640^{\circ}$ & $7,157^{\circ}$ \\
\hline Piropo & 11,459 & 2,5623 & $34,990^{\circ}$ & $26,640^{\circ}$ & $8,350^{\circ}$ \\
\hline Espessartita & 11,621 & 2,5985 & $34,487^{\circ}$ & $26,640^{\circ}$ & $7,847^{\circ}$ \\
\hline
\end{tabular}




\footnotetext{
2. almandina - andradita - piropo

3. almandina - andradita - espessartita

4. almandina - grossulária - piropo

5. almandina - grossulária - espessartita

6. almandina - piropo - espessartita

7. andradita - grossulária - piropo

8. andradita - grossulária - espessartita

9. andradita - piropo - espessartita

10. grossulária - piropo - espessartita
}

Nos nomogramas de 1 a 10 estão associados $\triangle 2 \theta$ e $n ;$ de 11 a $20, \triangle 2 \theta$ e D e de 21 a 30, n e D. Nessas condições elabora-se uma série de 30 gráficos triangulares, que podem identificar a mistura isa morfa, fornecendo a percentagem de seus três principais com ponentes. Apesar de não estar assinalada, a composição quí mica correspondente a qualquer ponto do triângulo pode ser determinada, desde que, se considere cada vértice como $100 \%$ da espécie e os respectivos lados opostos a $0 \%$ 。 


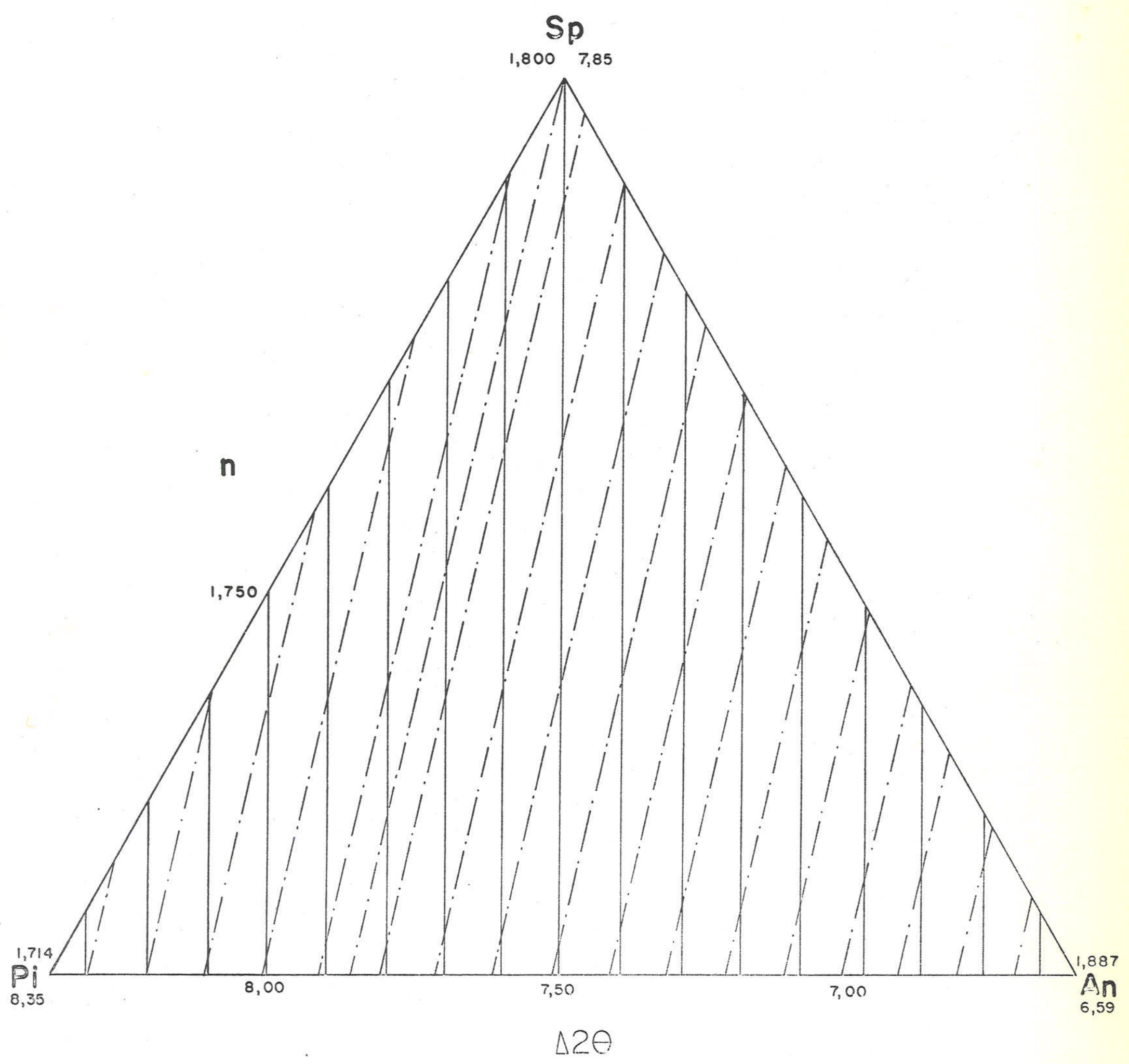




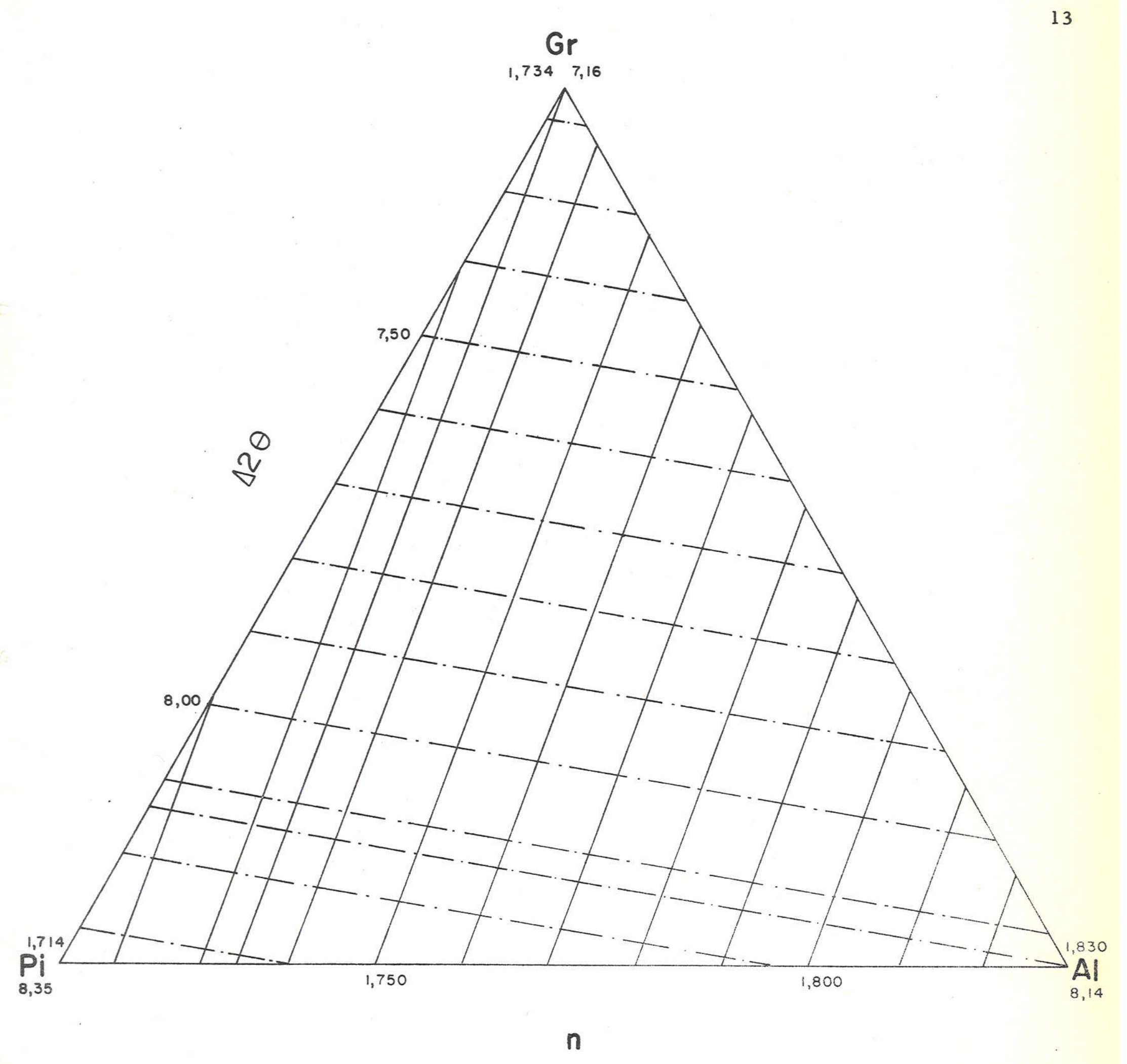




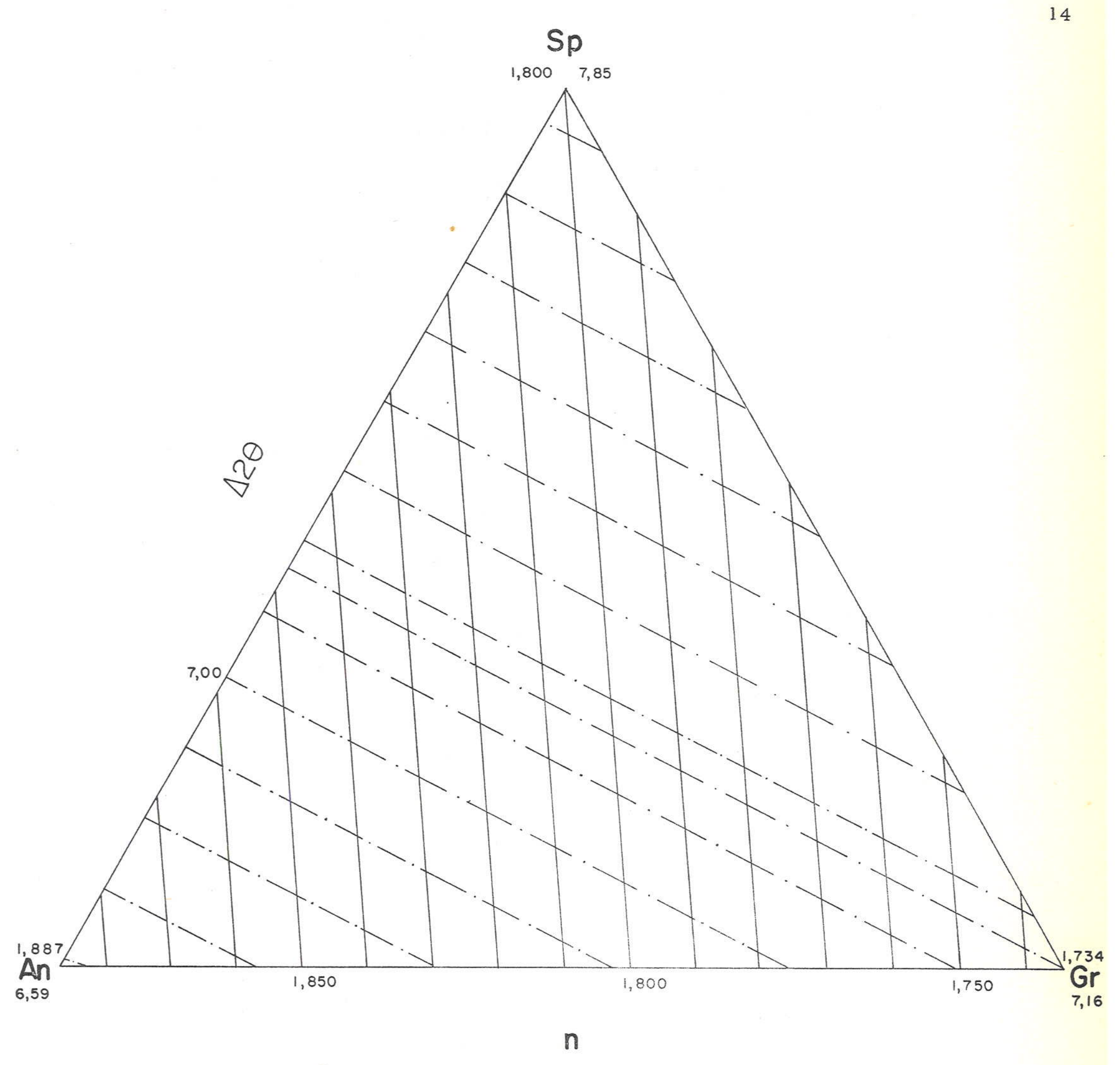




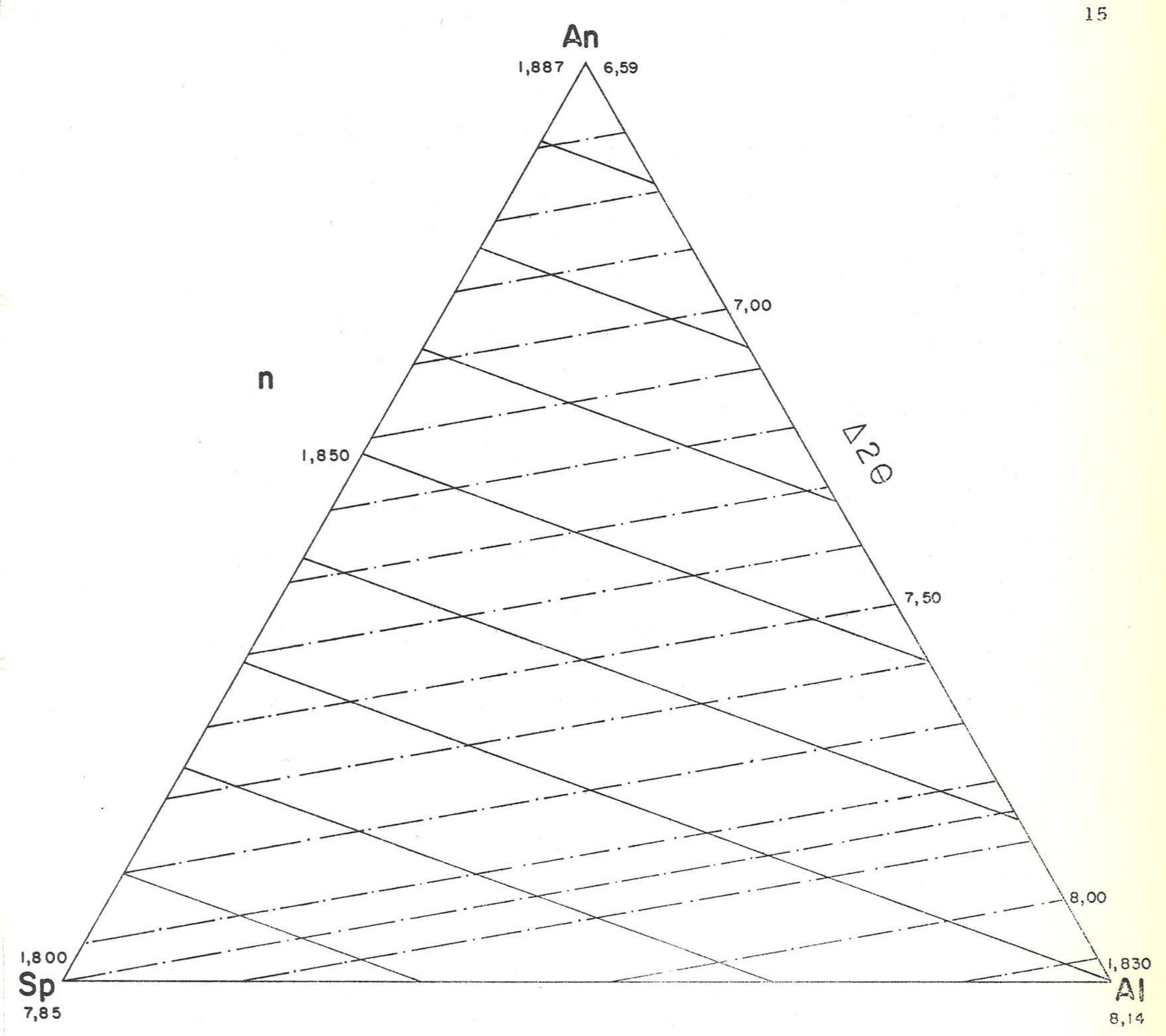




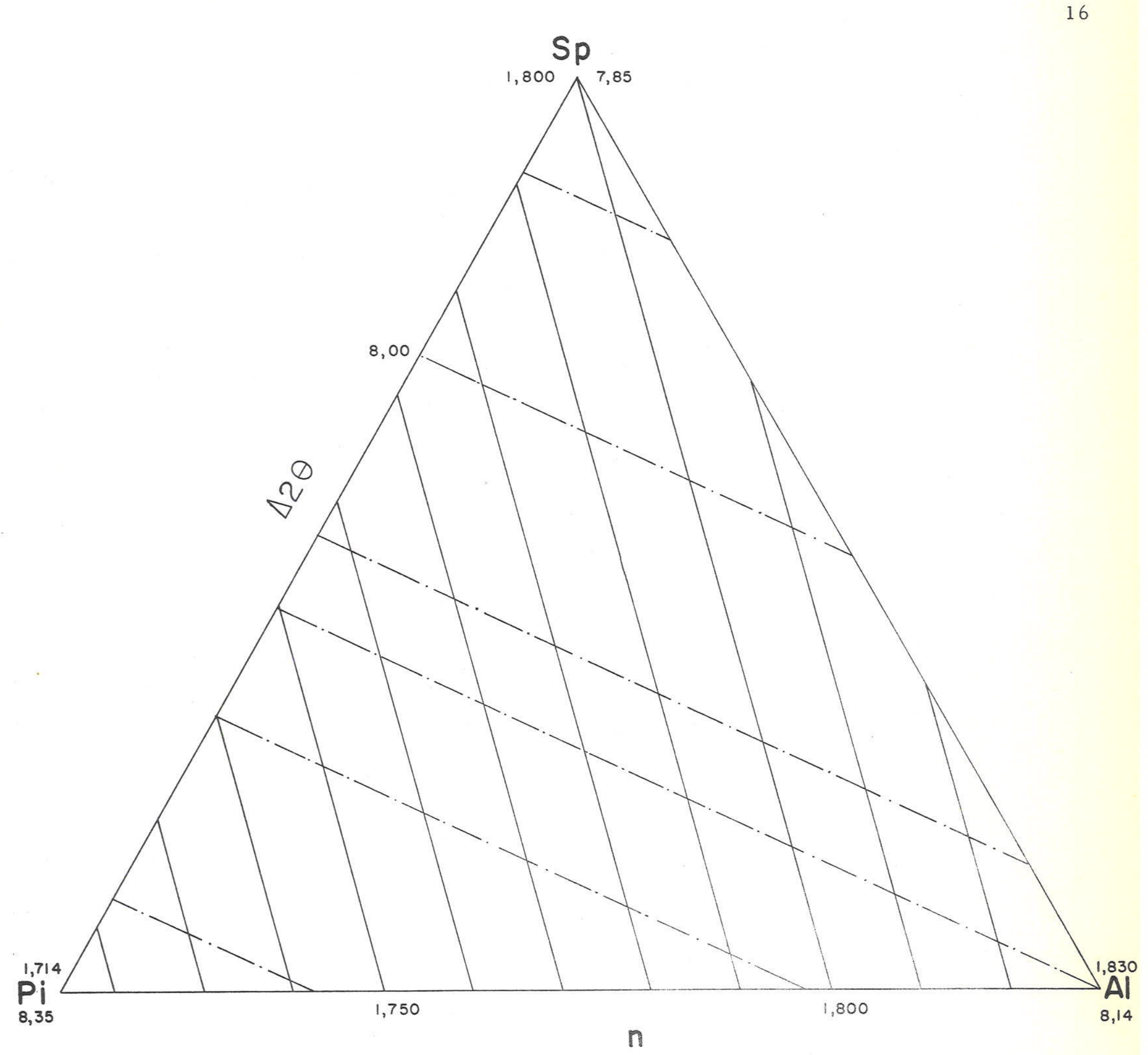




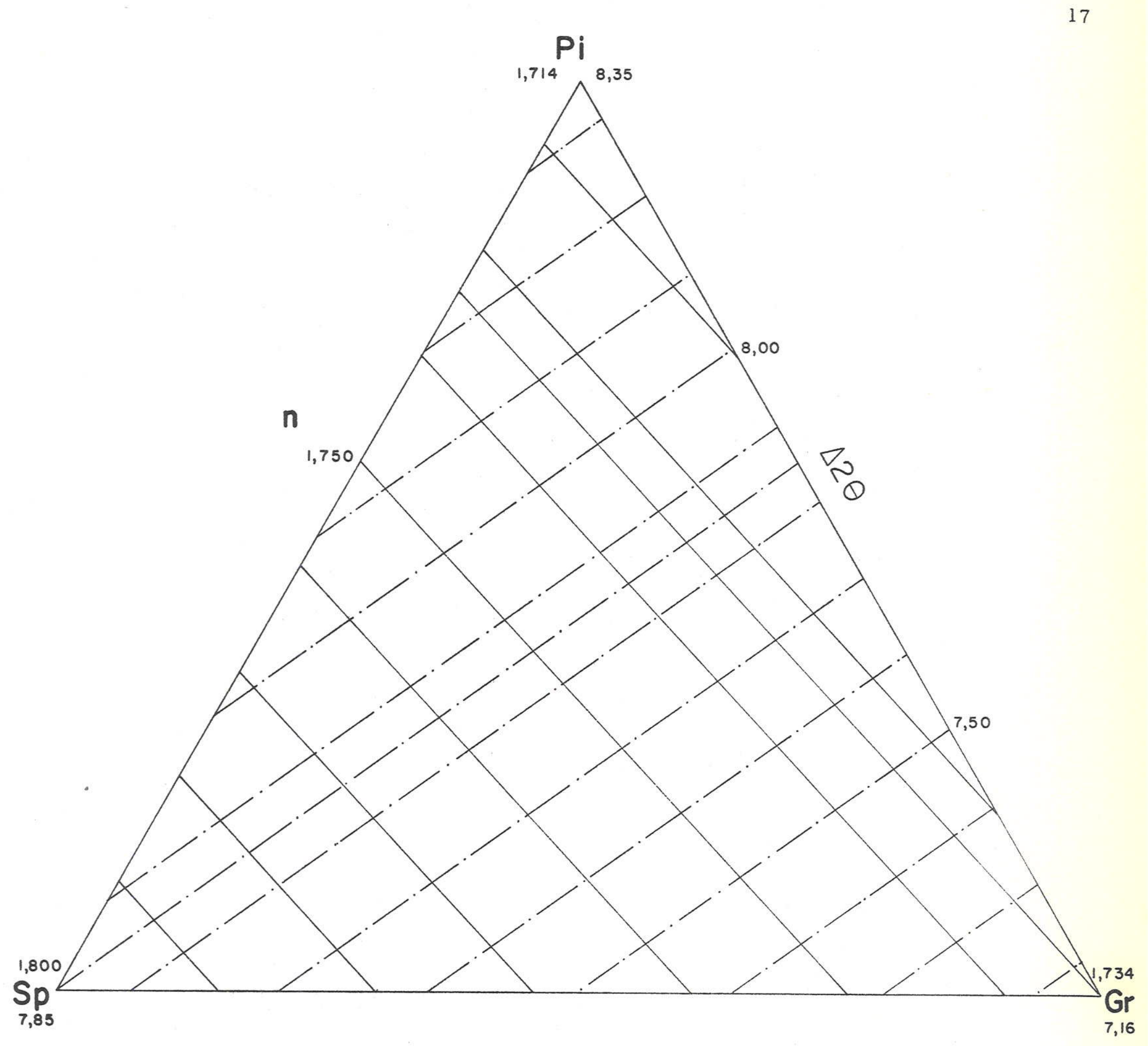




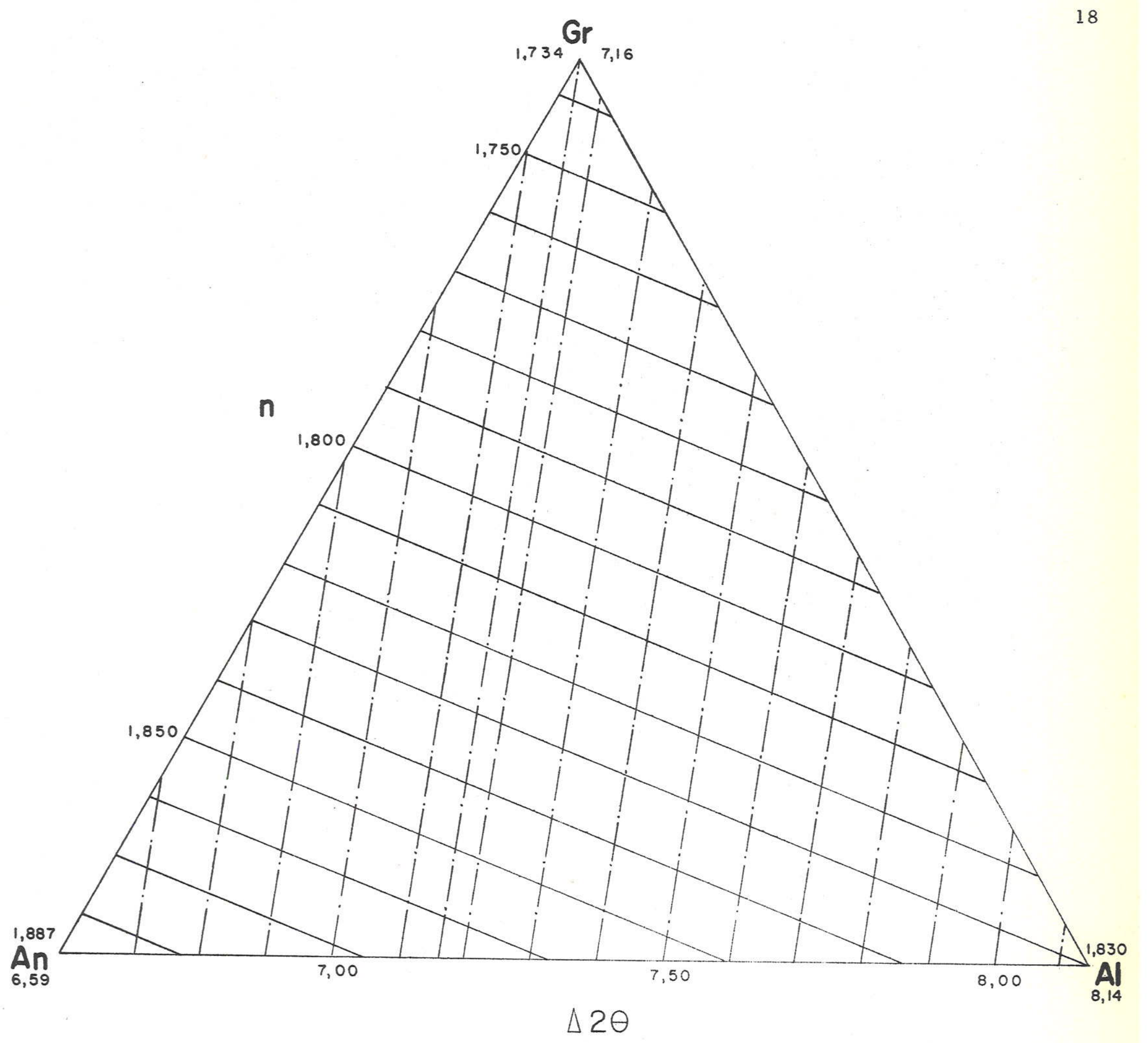




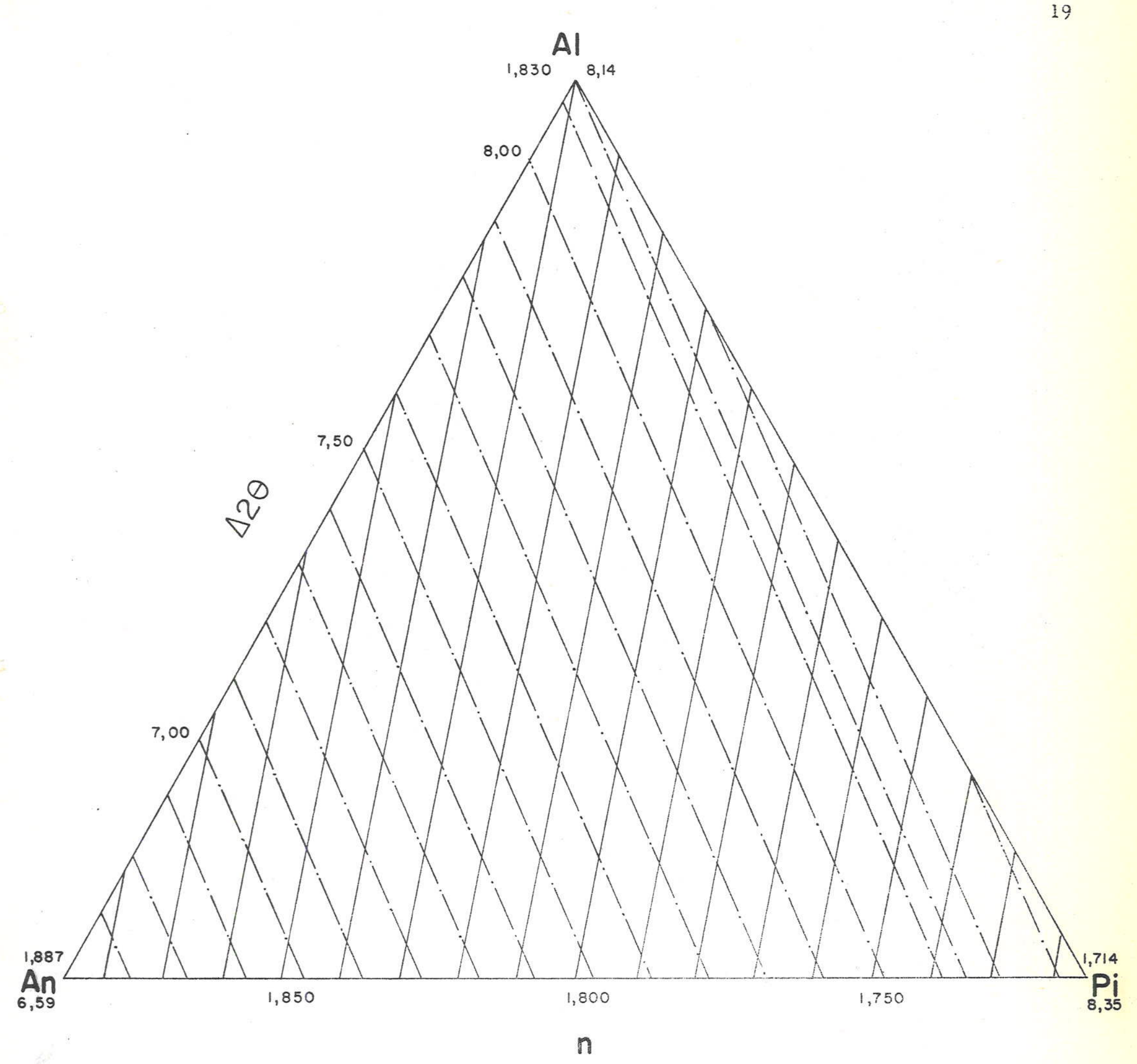




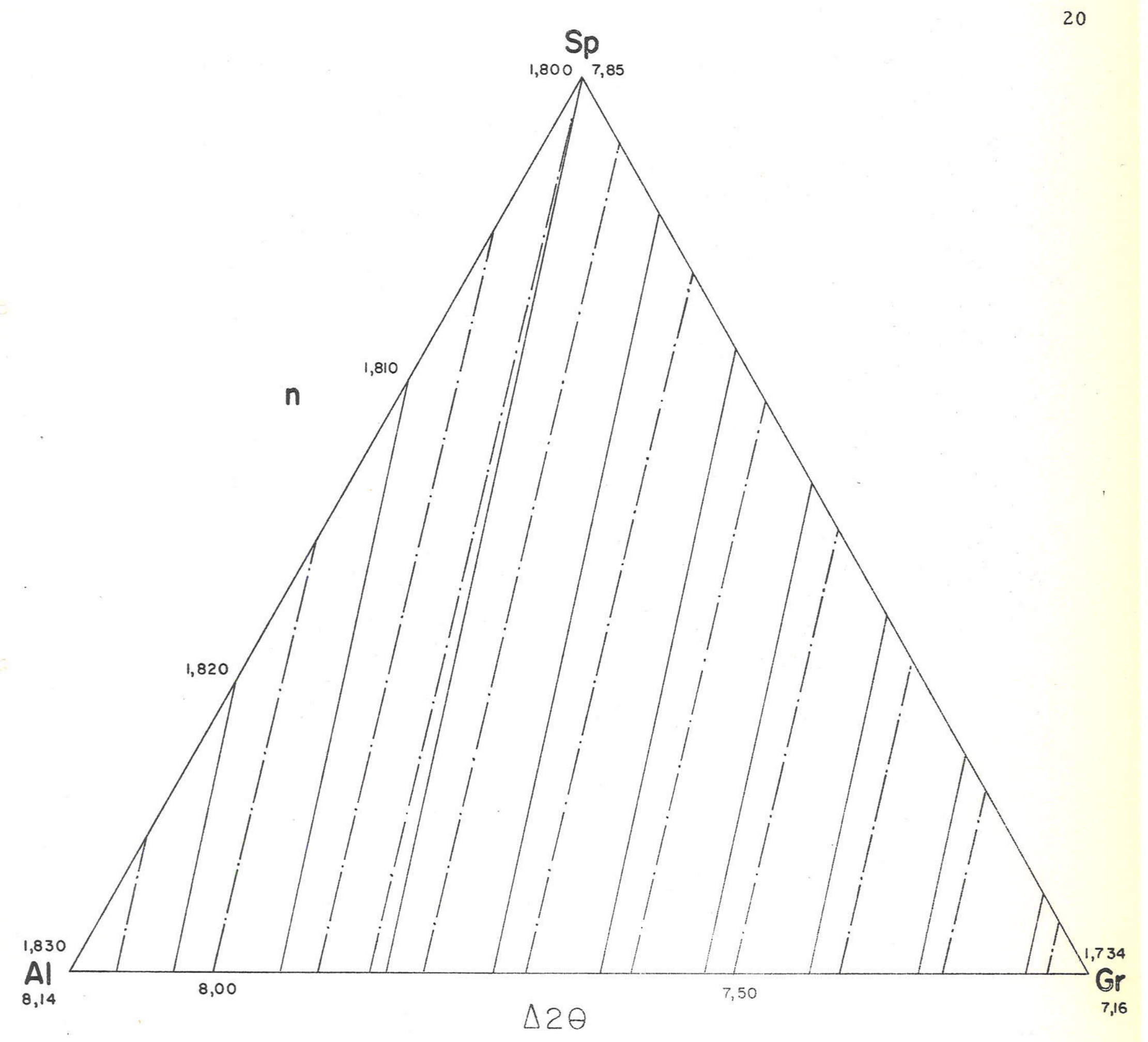





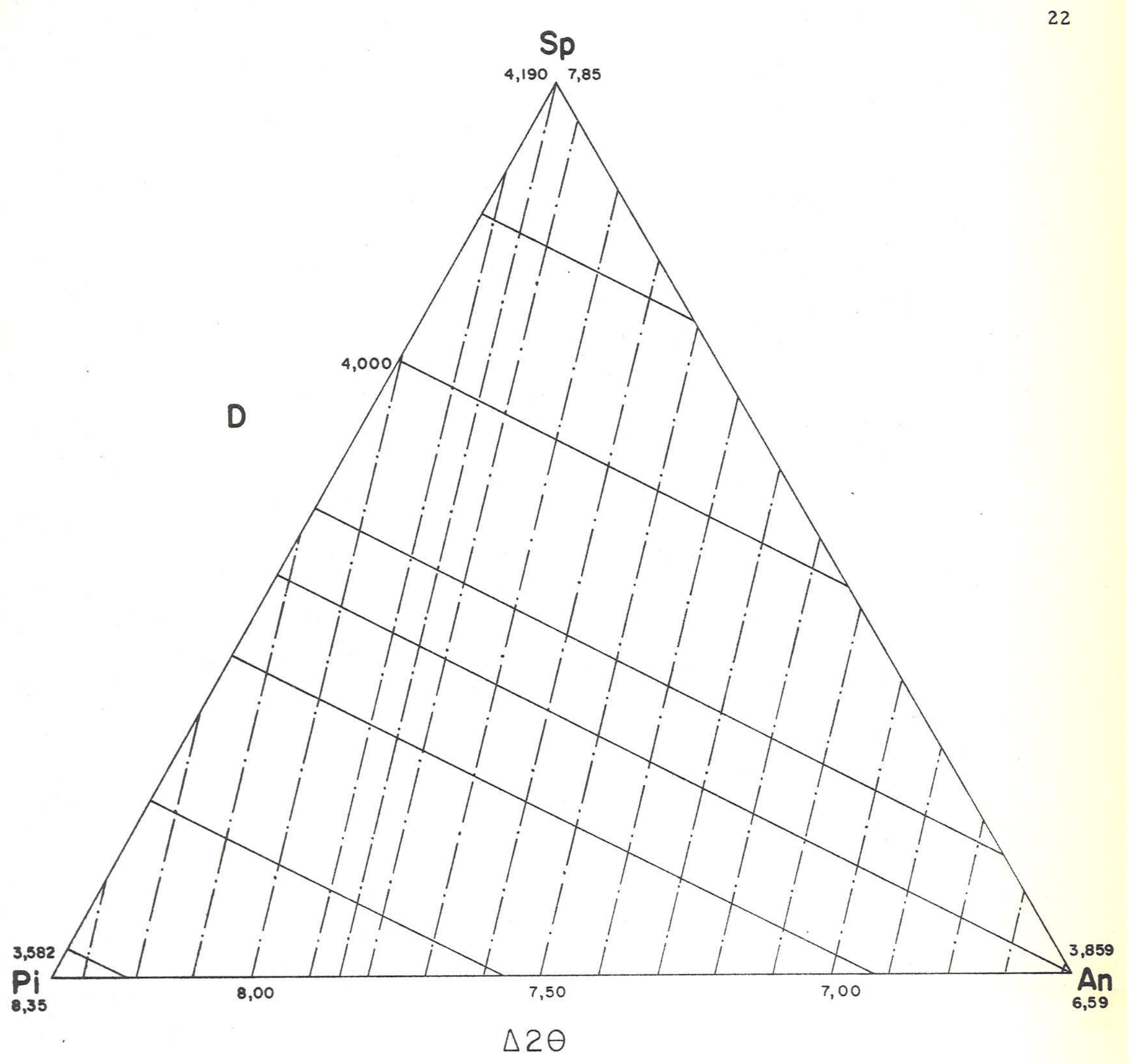




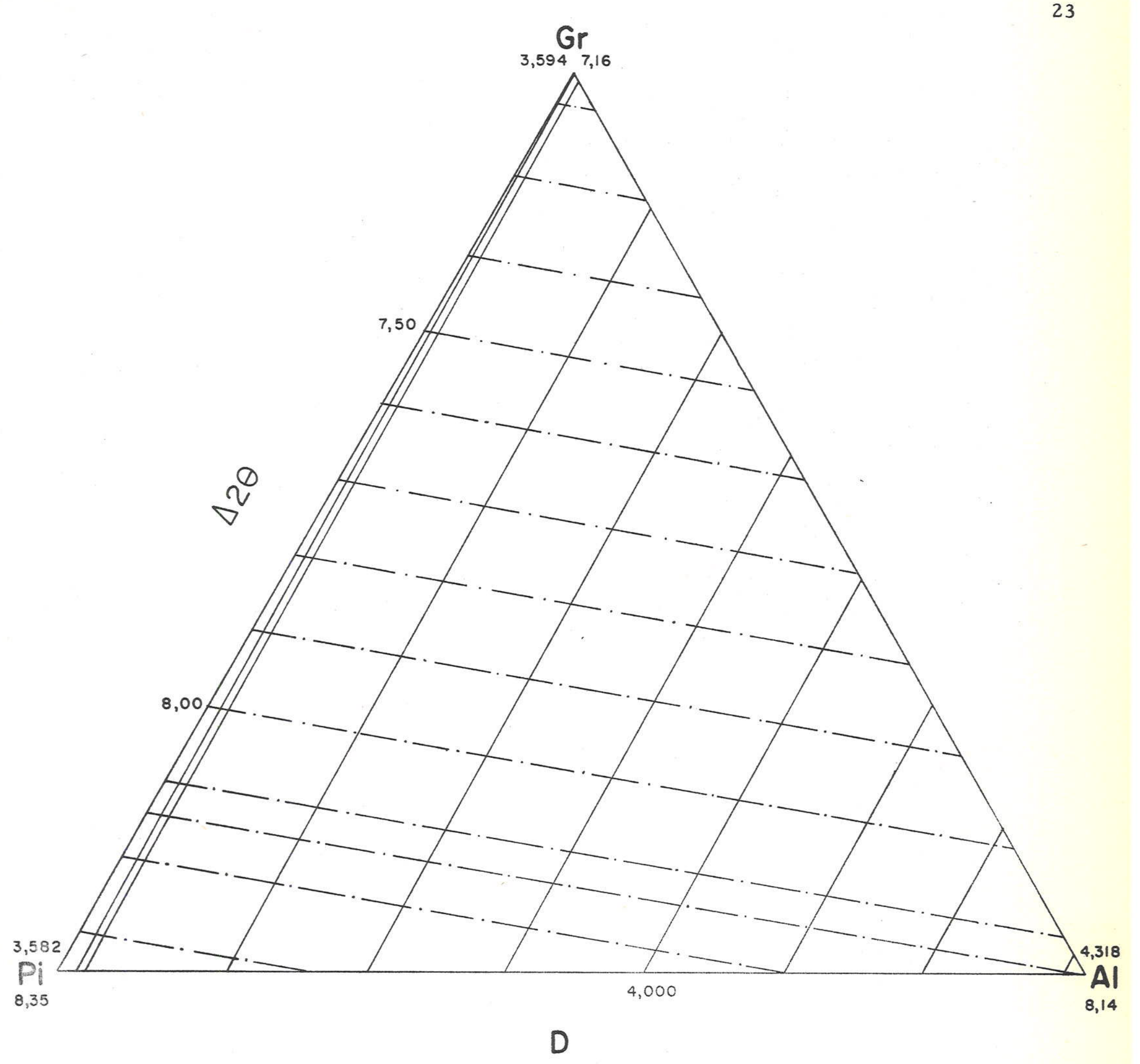




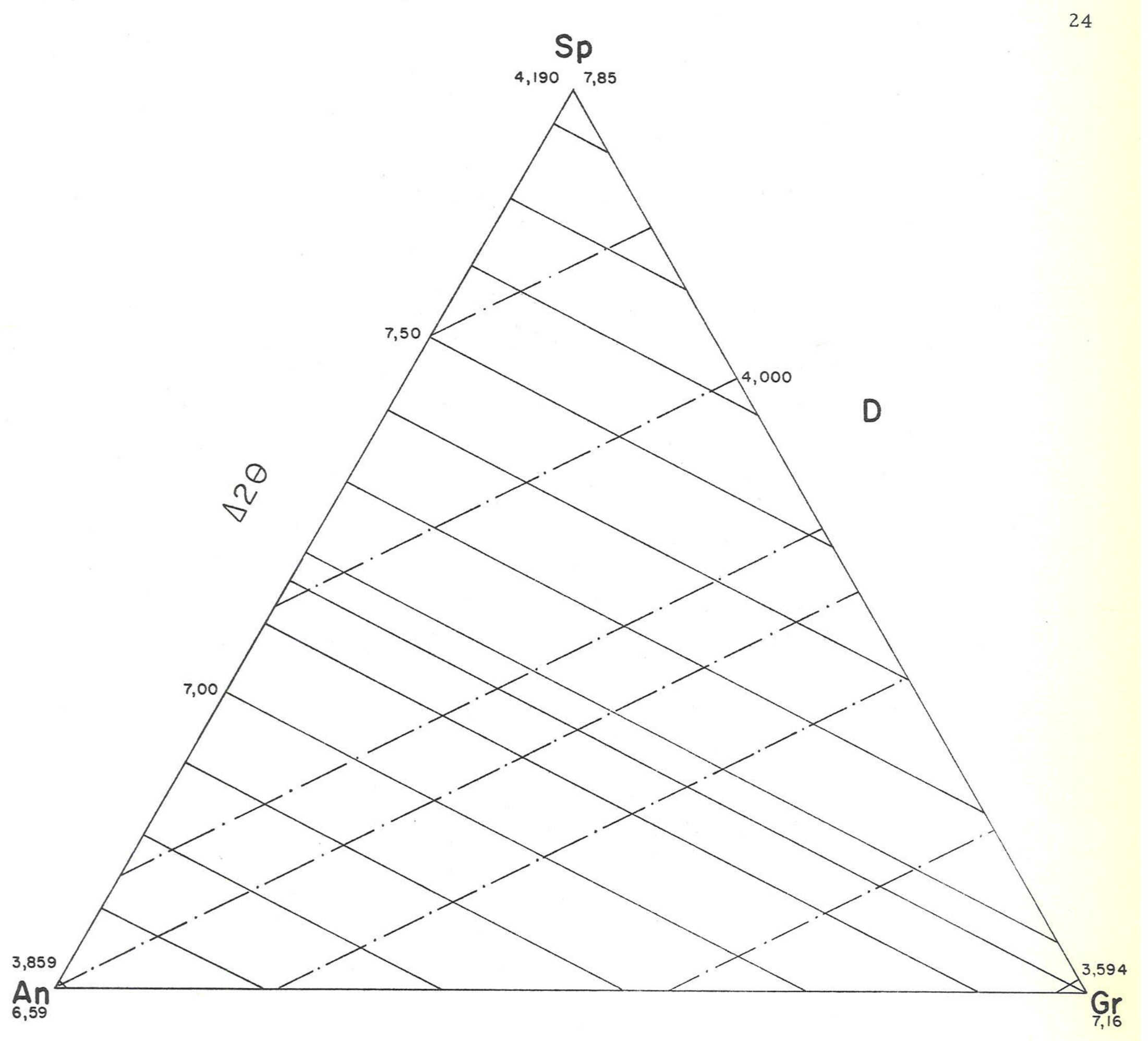




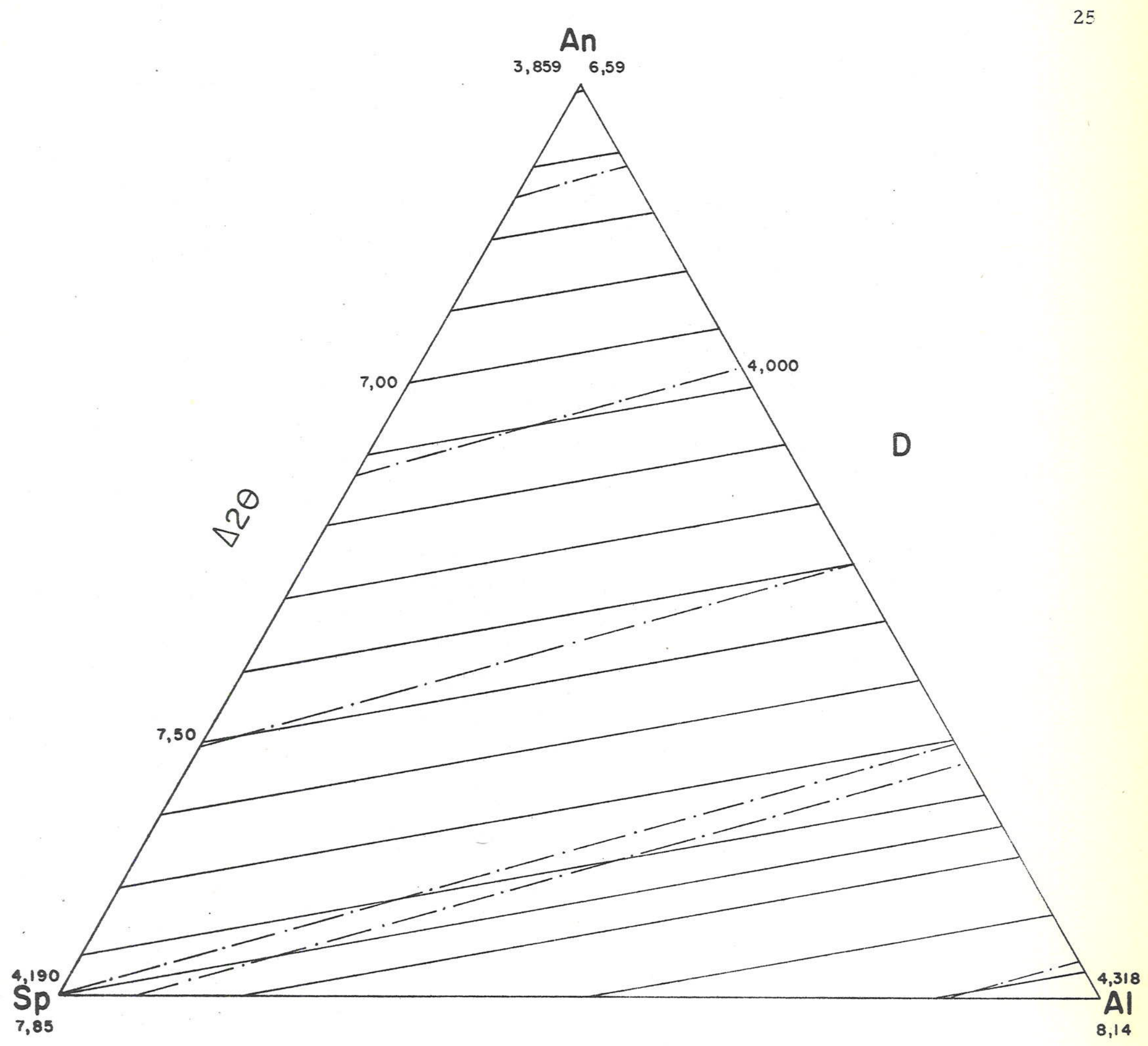




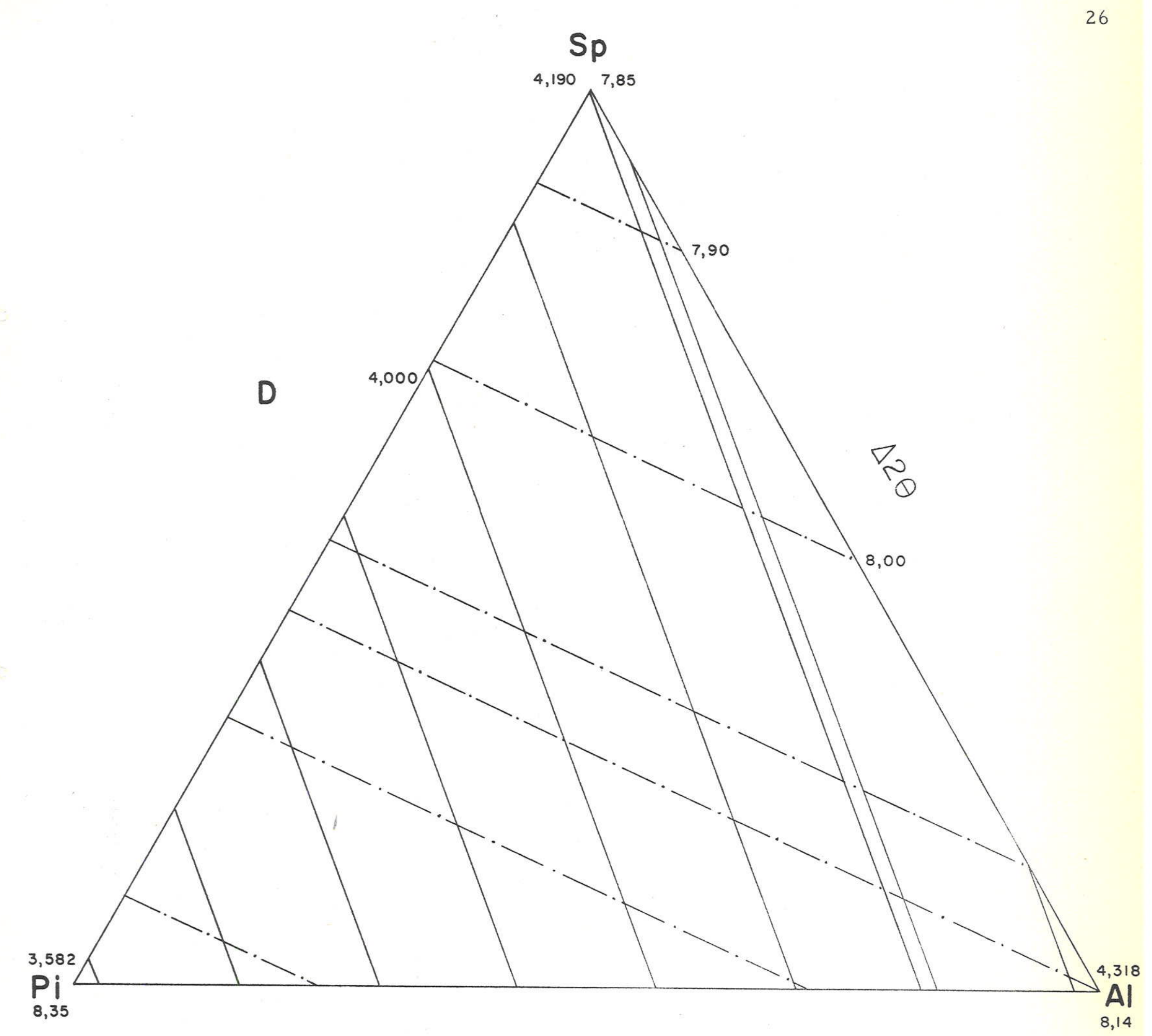




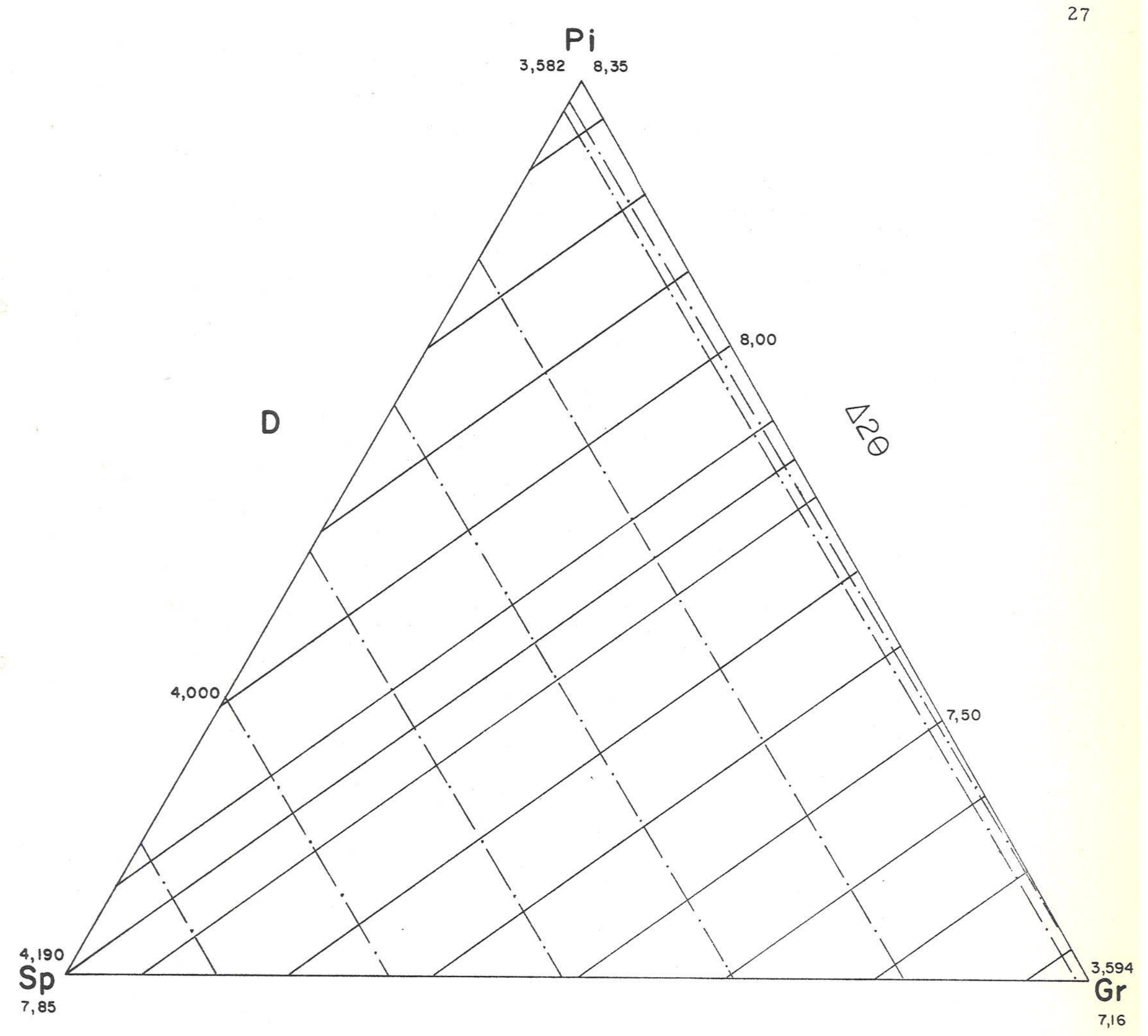




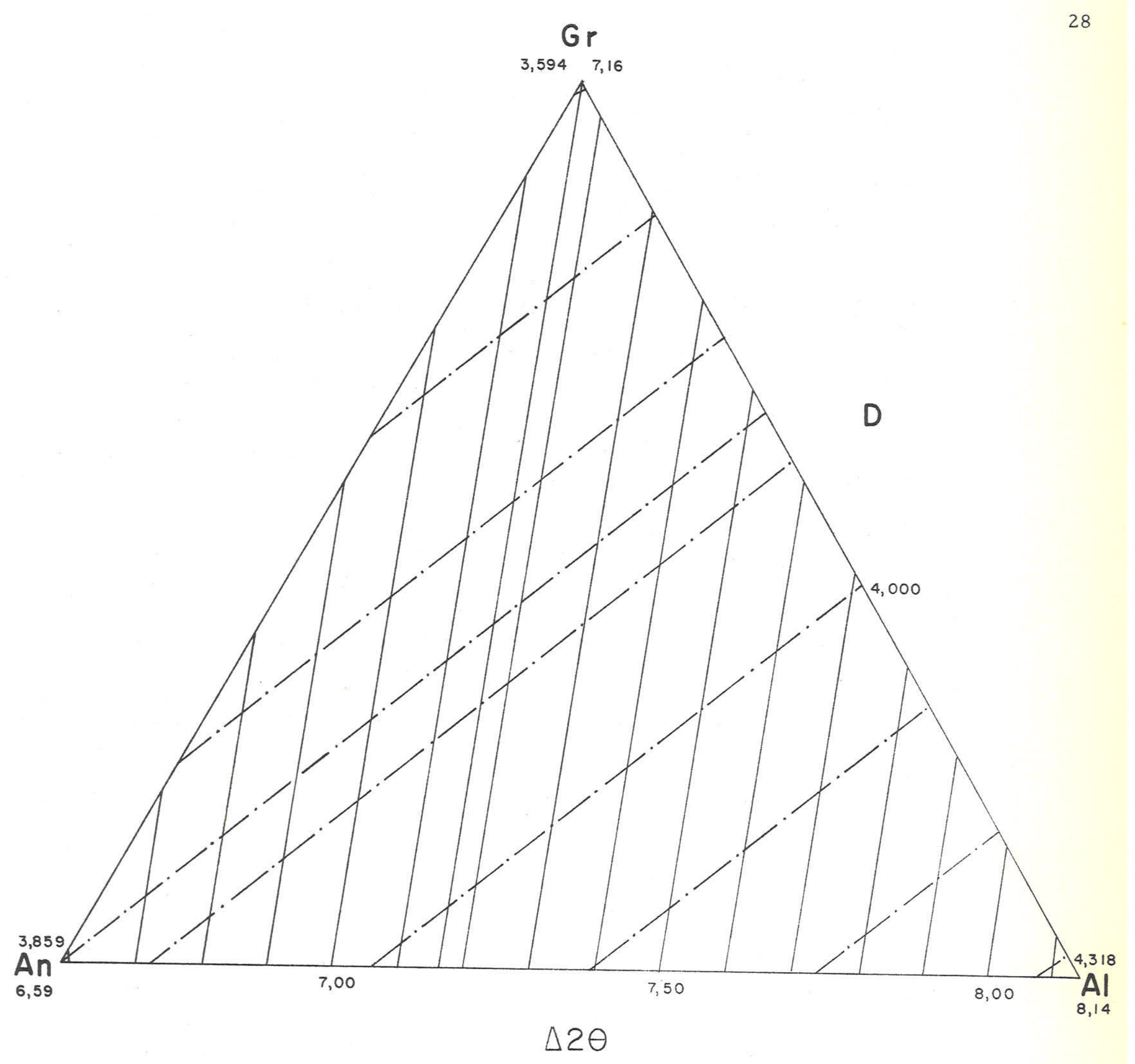




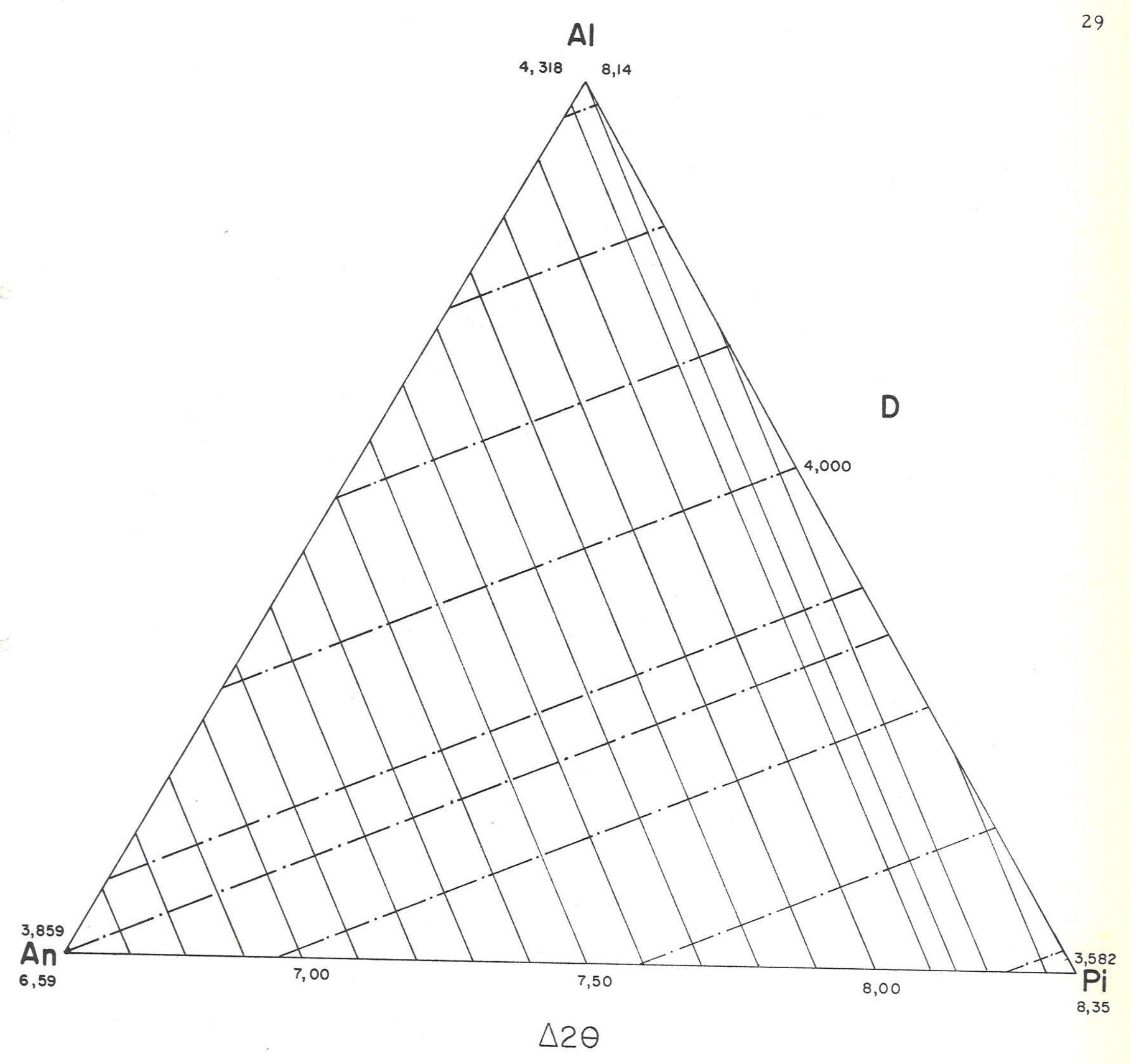




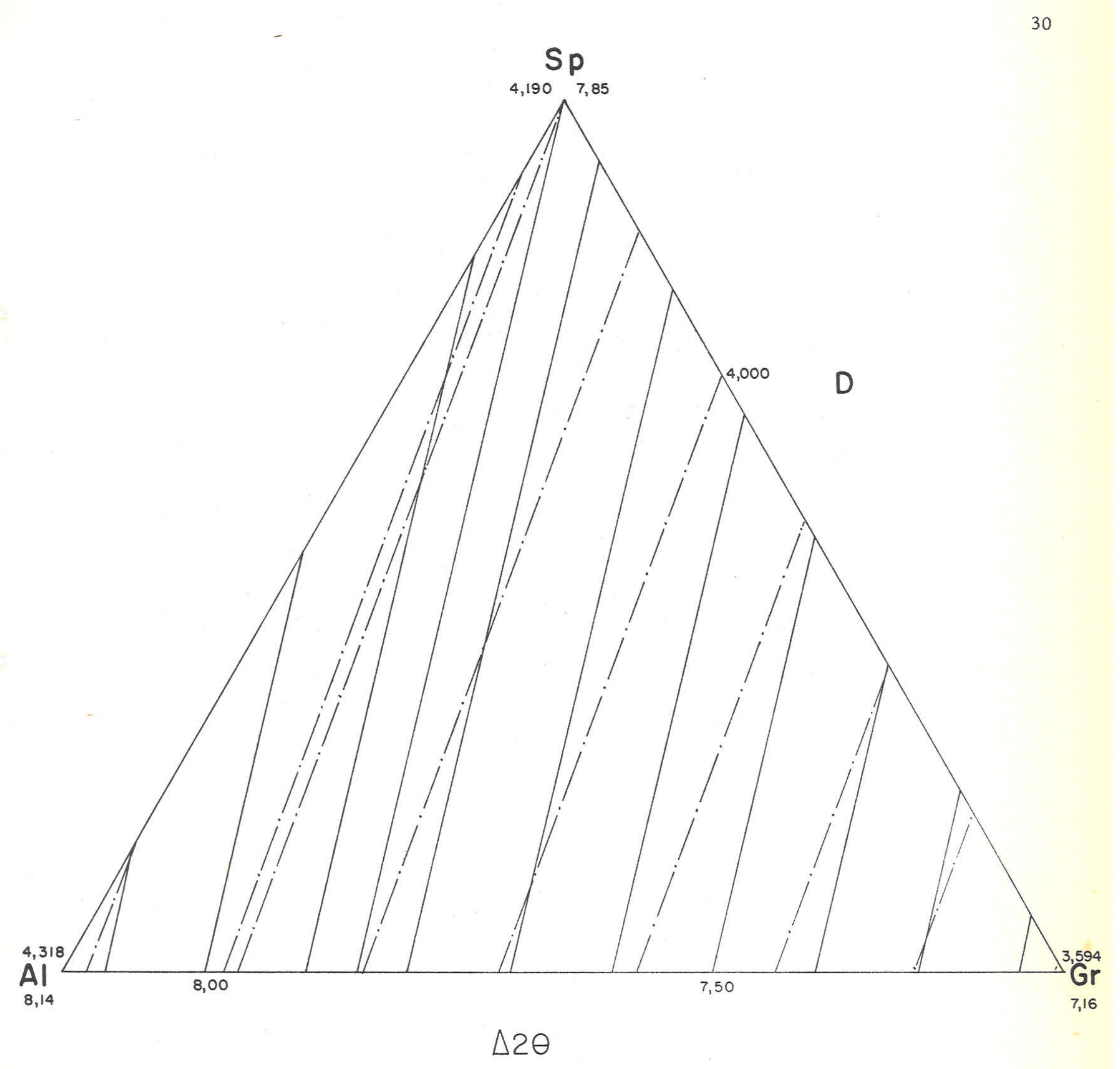




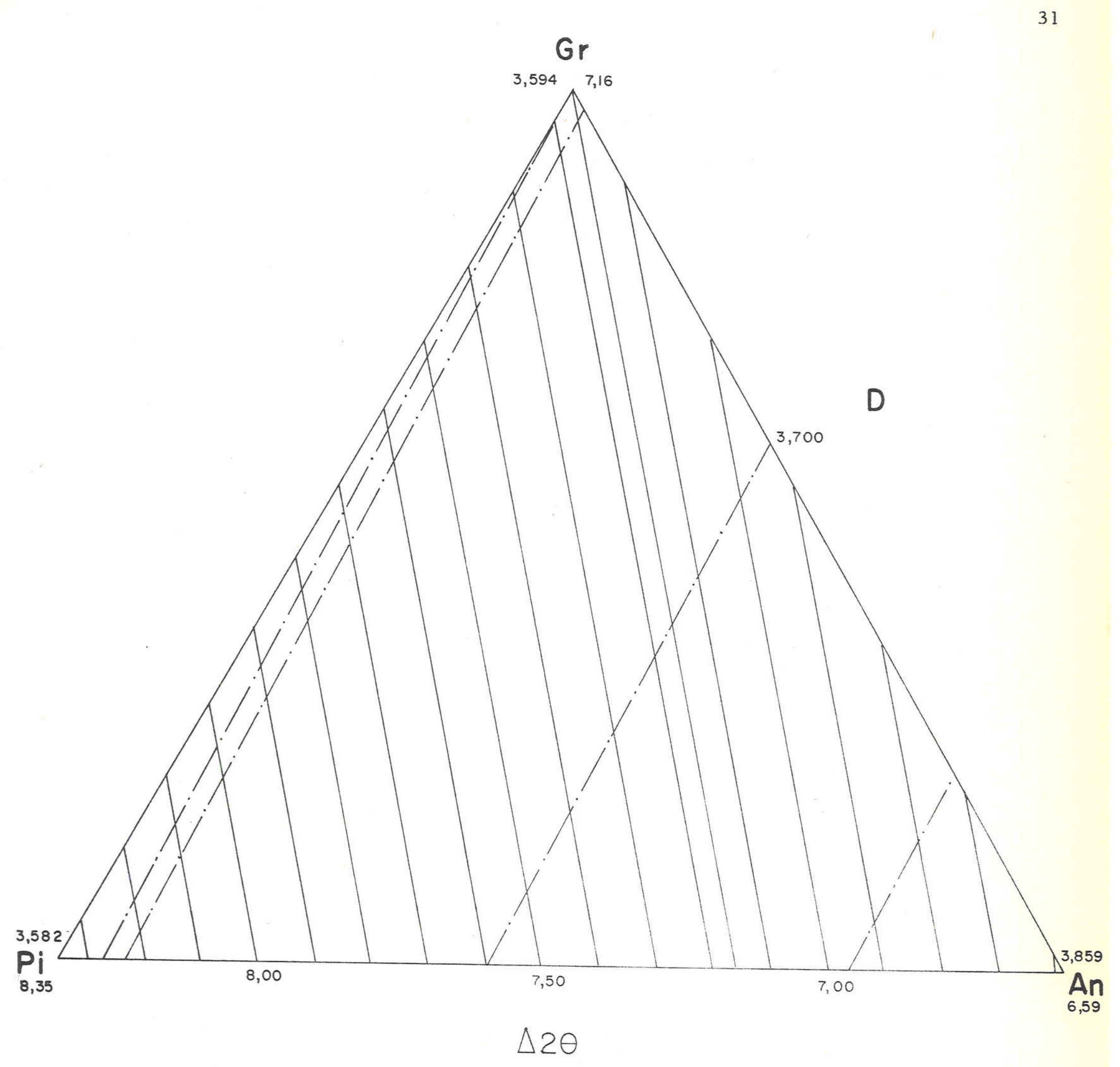




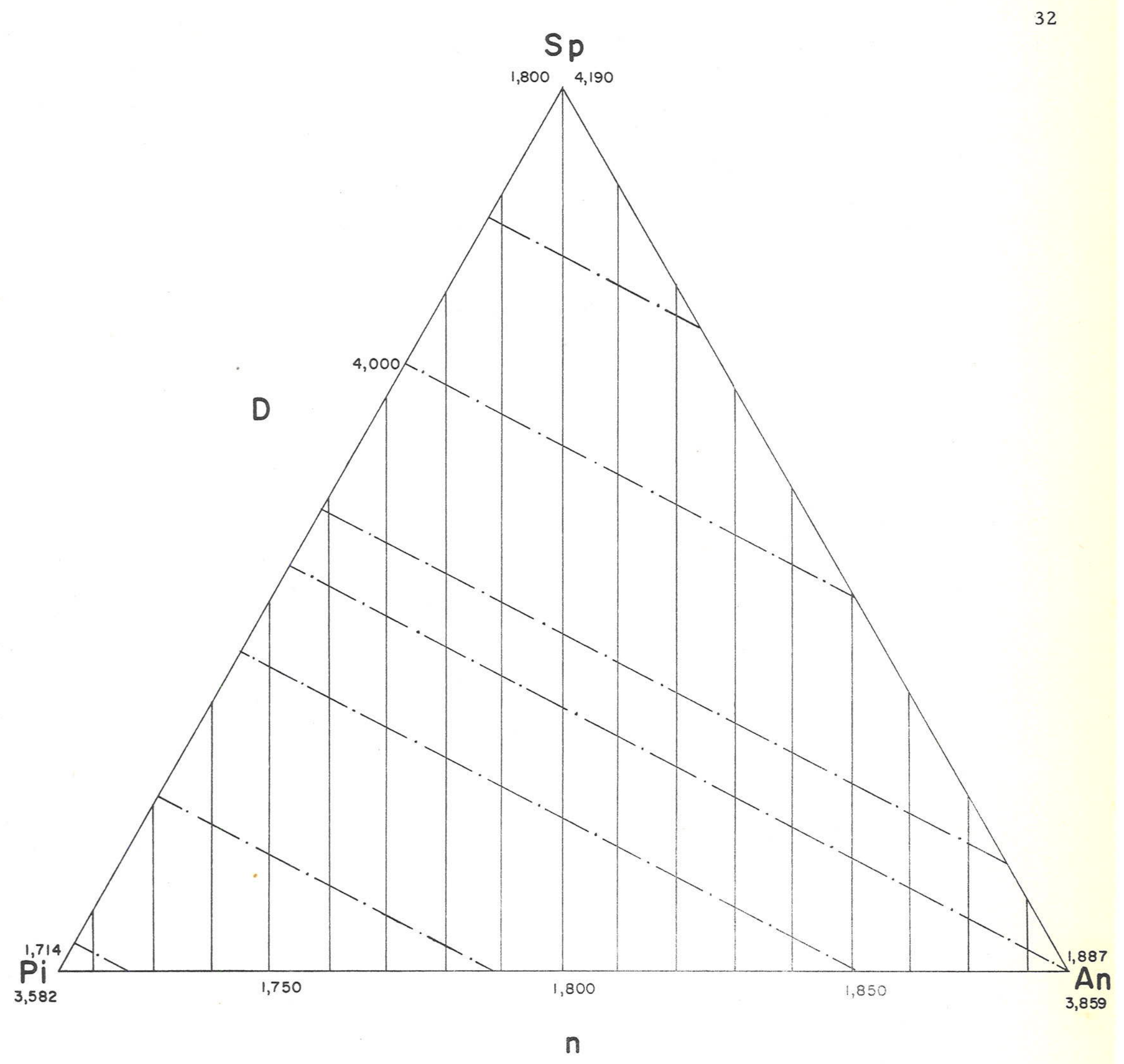




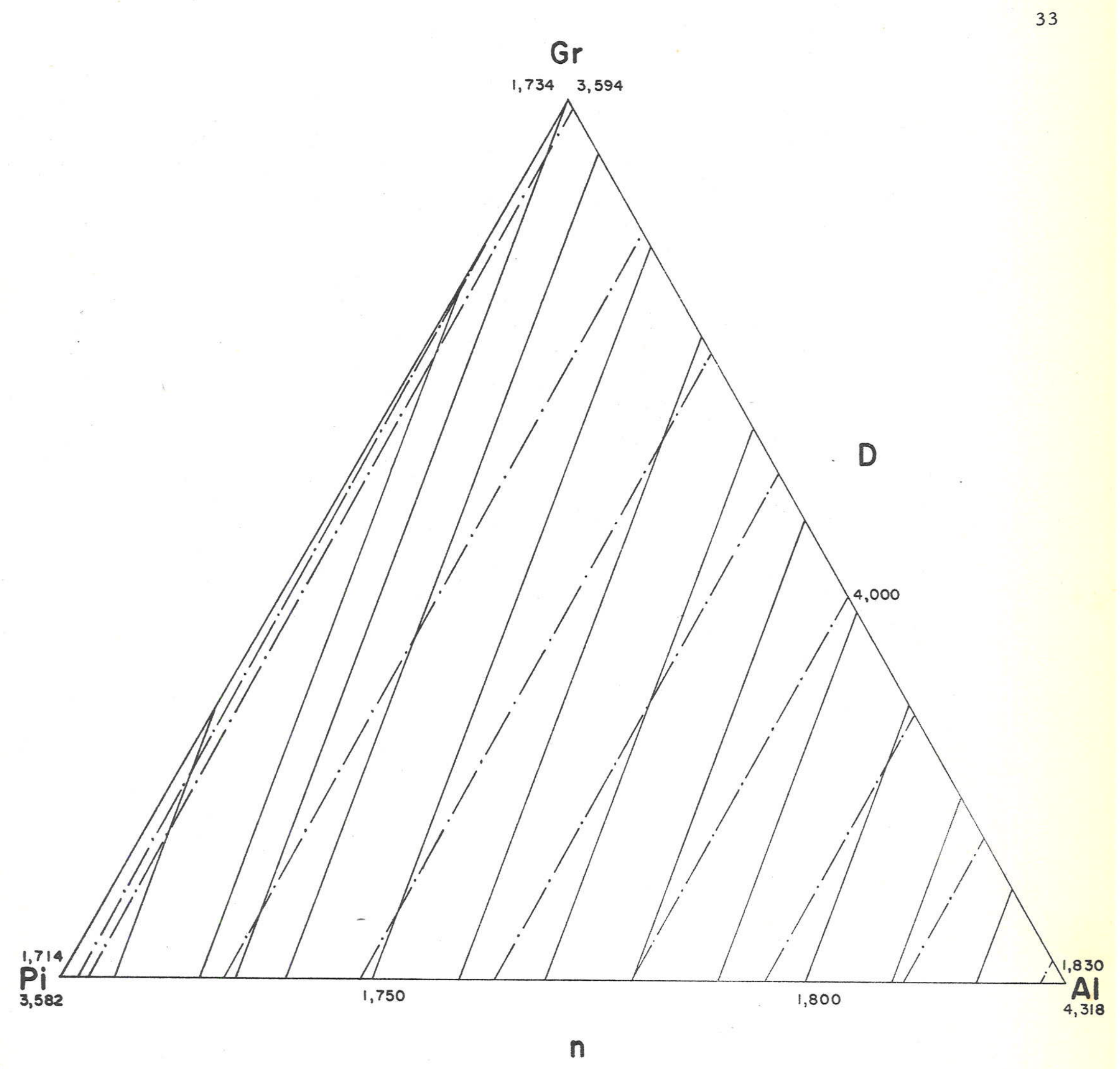




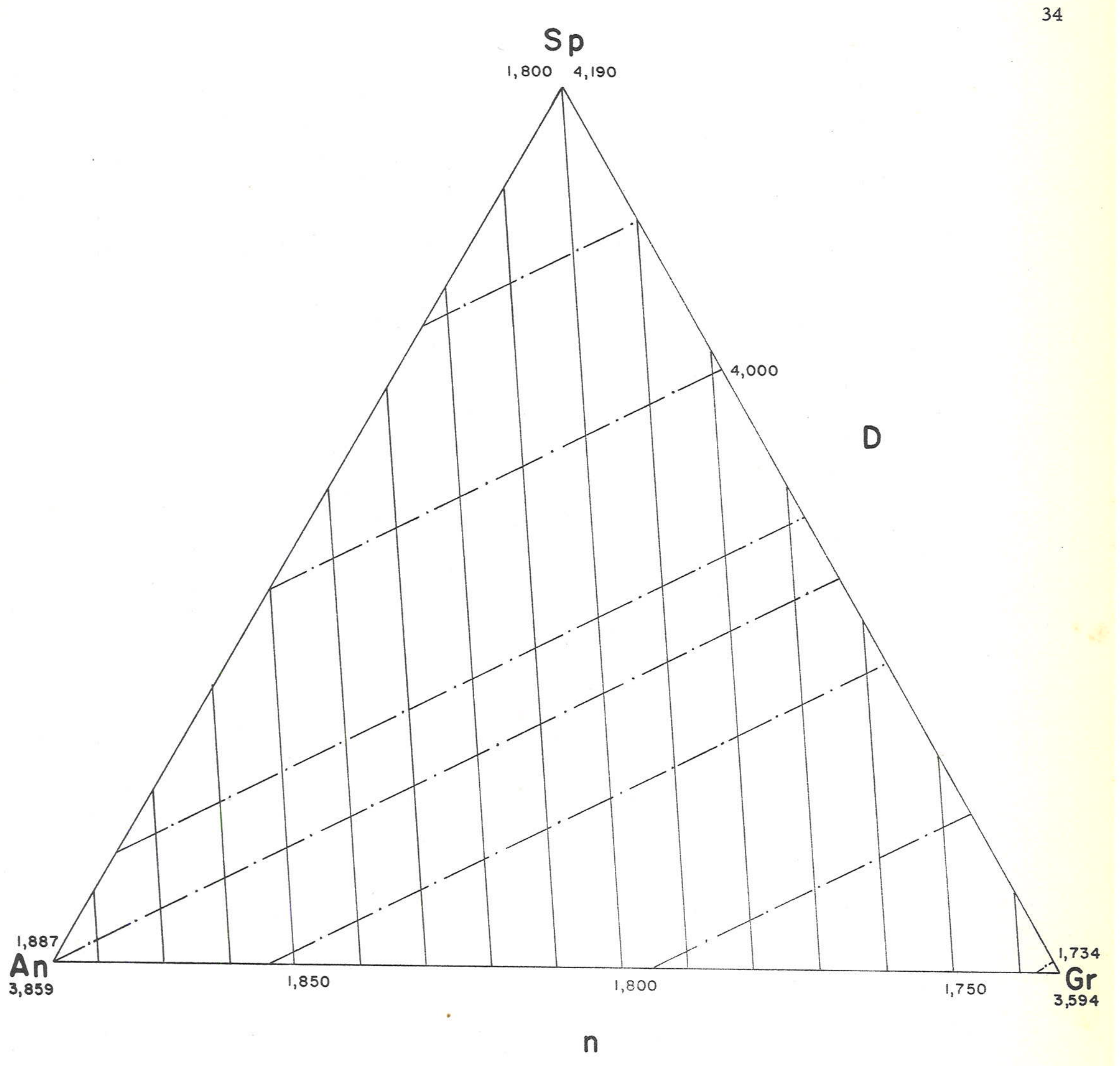




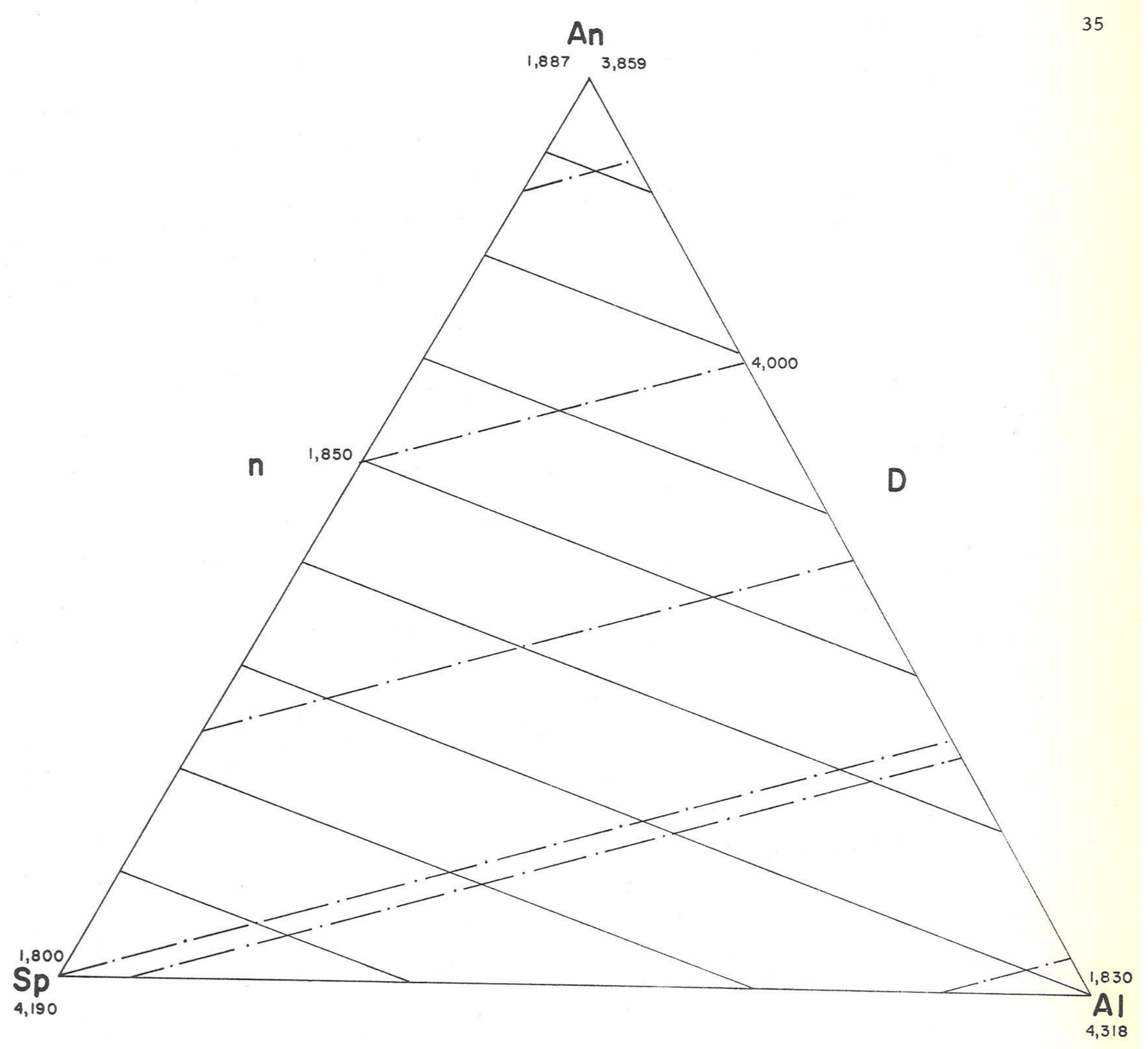




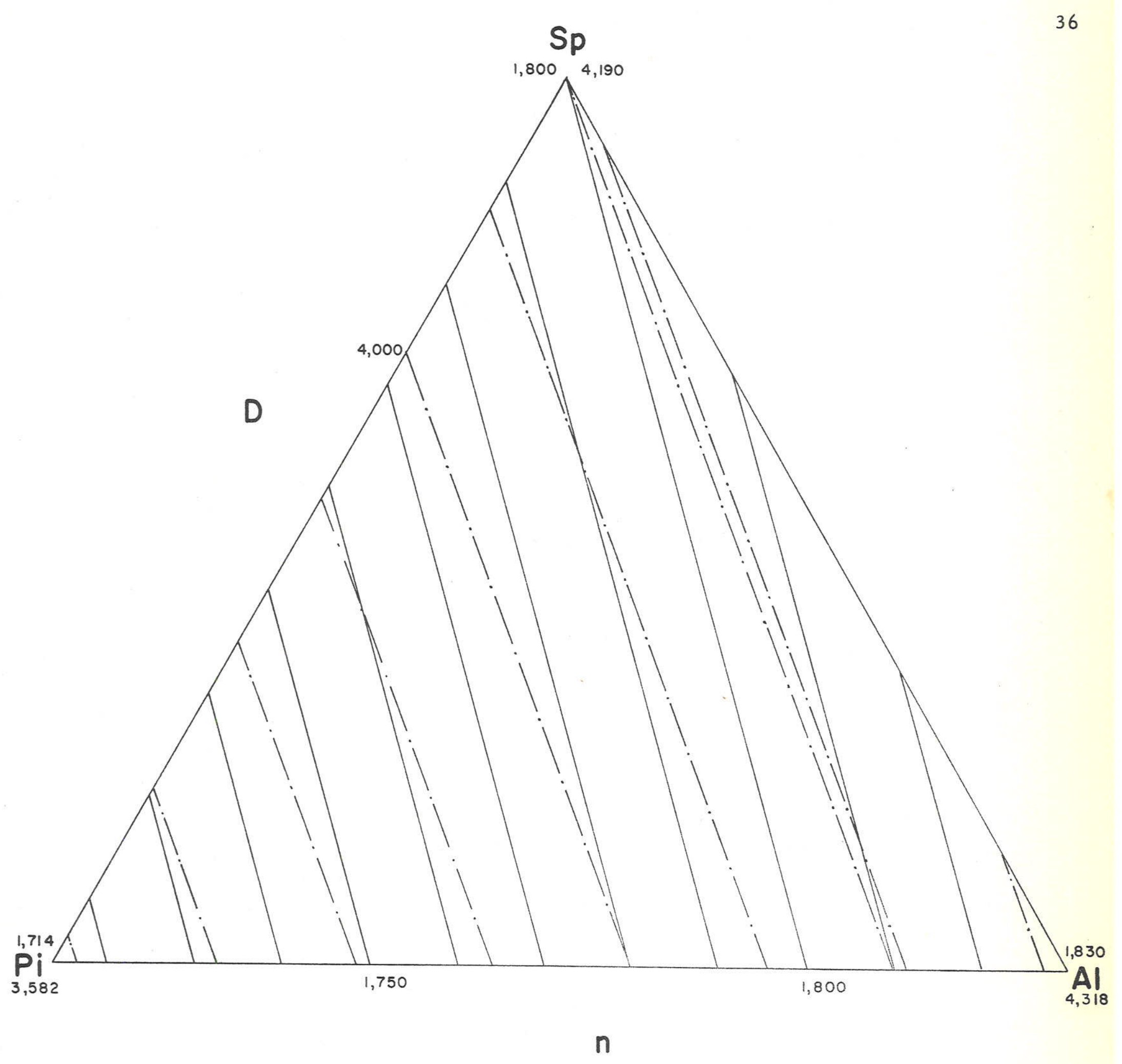




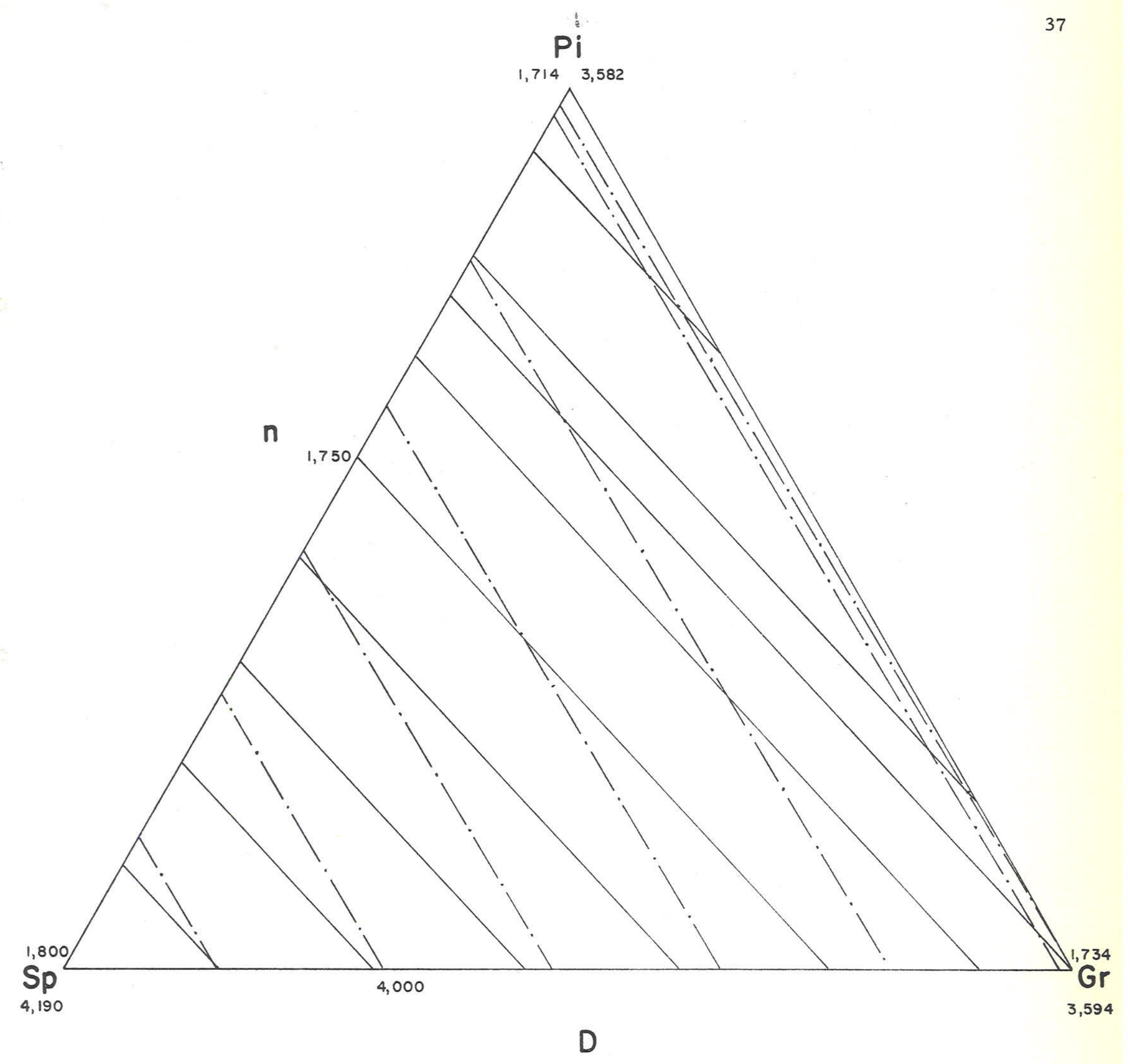




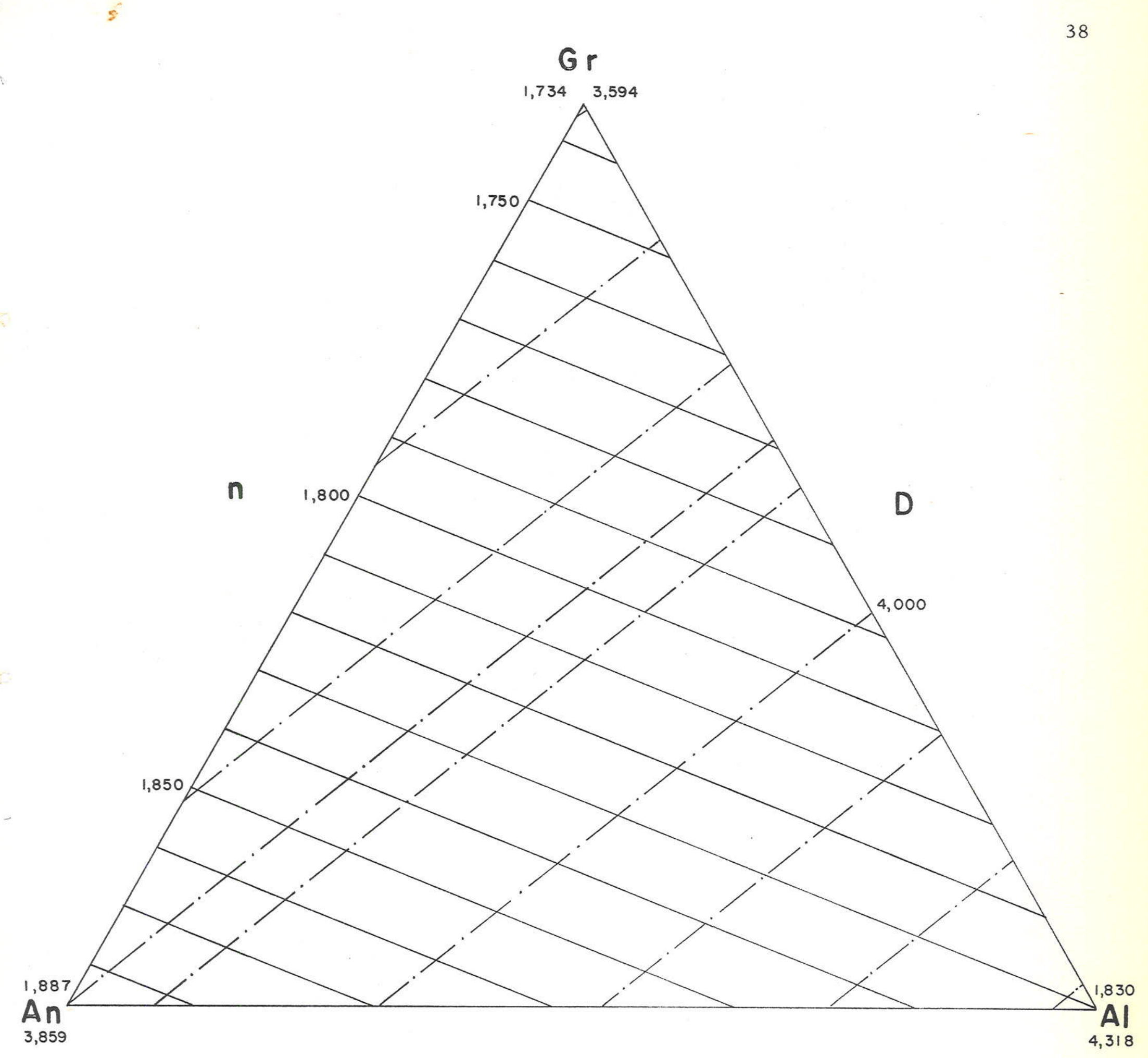




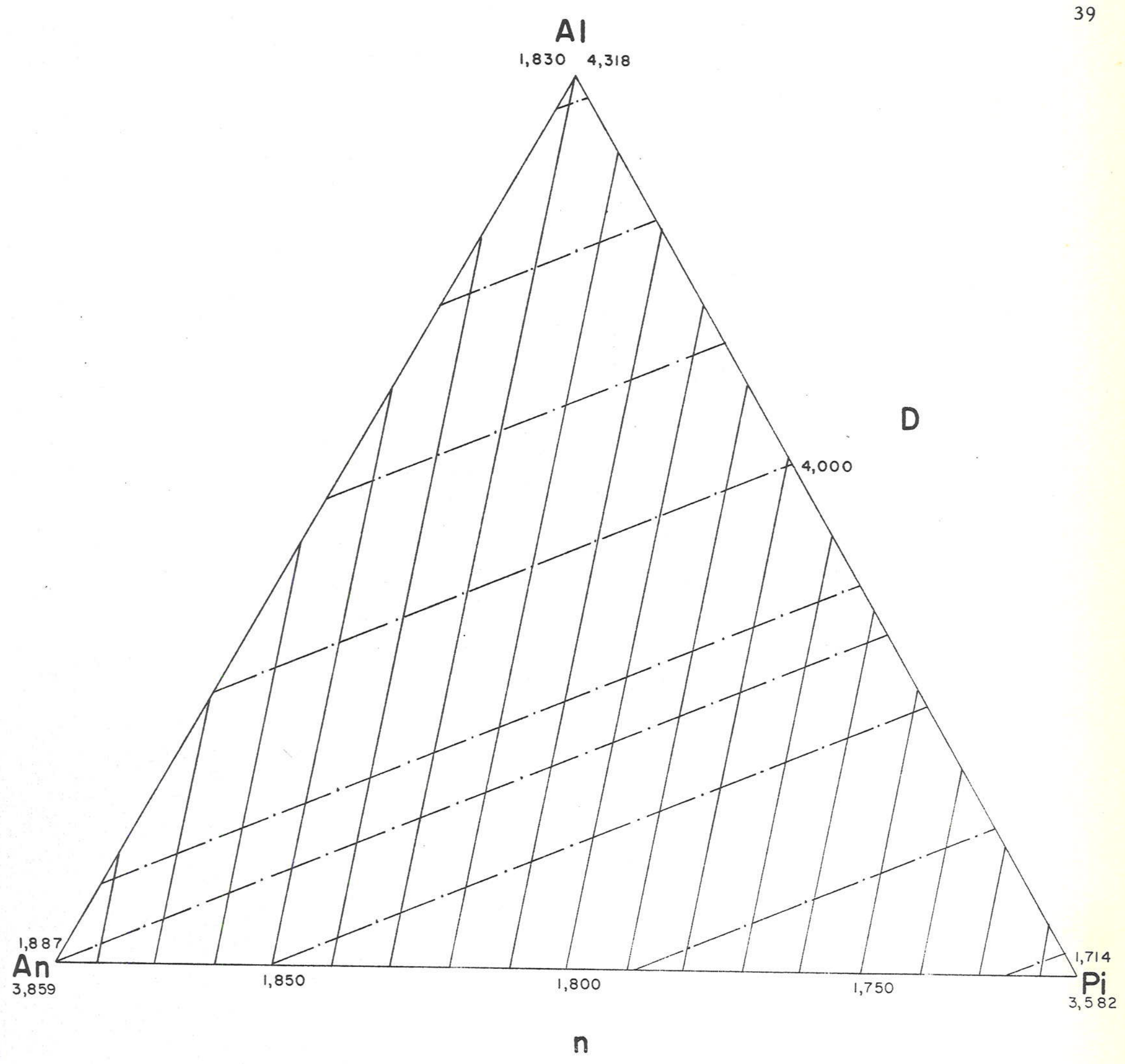




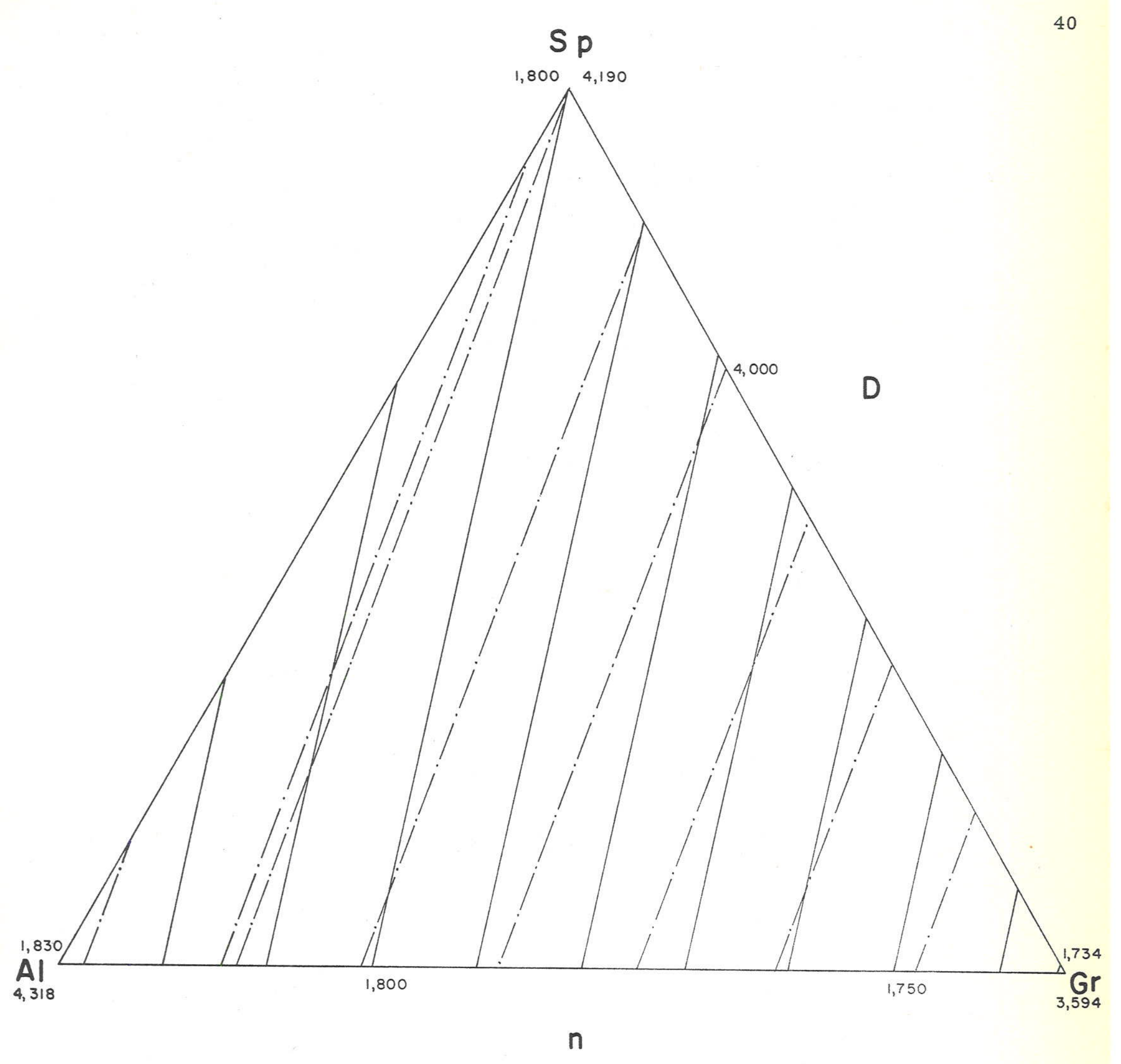




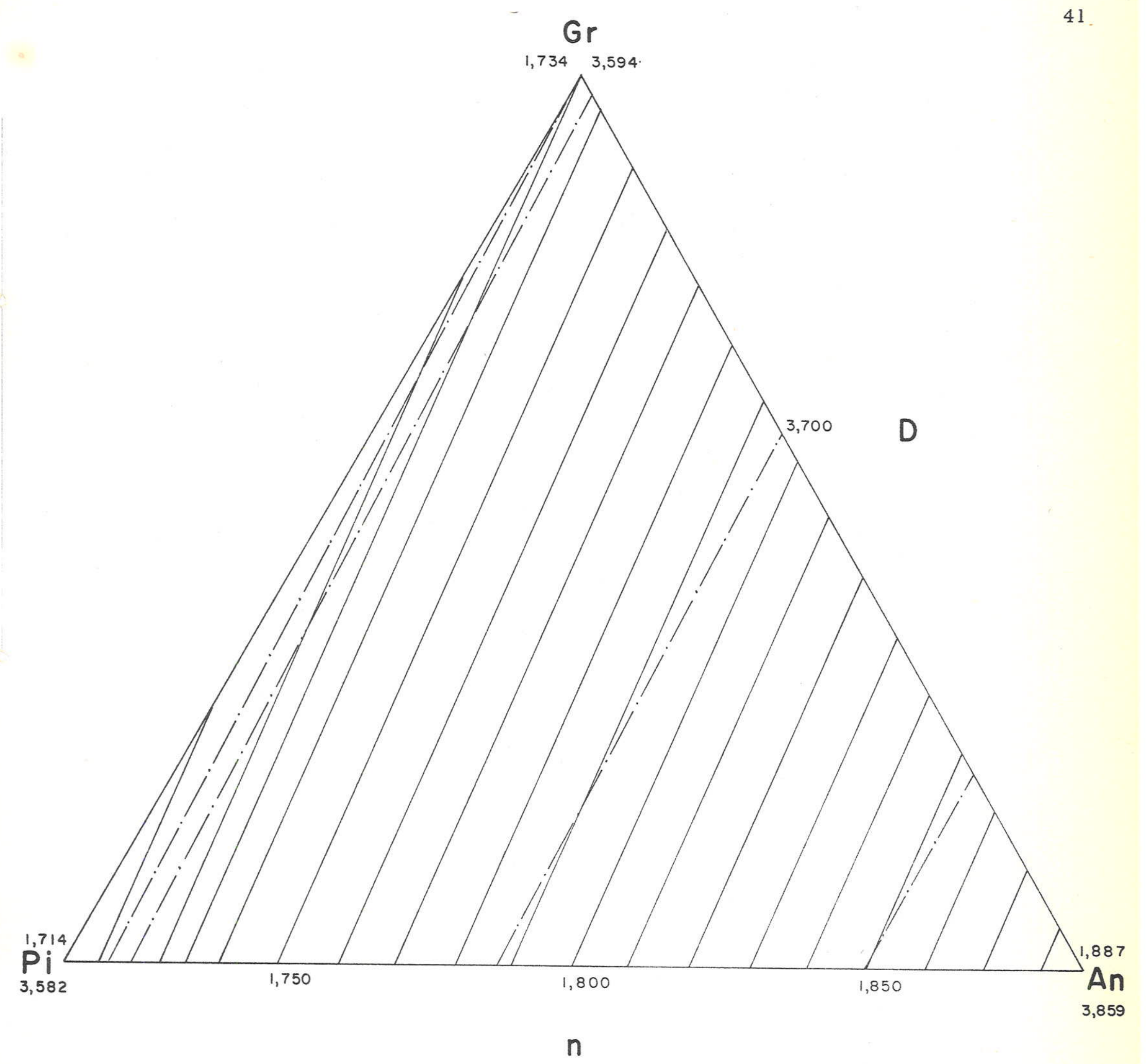


TABELA 5

Dados físicos e químicos de granadas, tomadas como exemplos

\section{Composição} molar

Almandina

Andradita

Grossulária

Piropo

Espessartita

\section{4, $0 \%$}

$$
0,2 \%
$$

$7,6 \%$

$0,9 \%$

$87,3 \%$
$76,7 \%$

2, $1 \%$

$3,1 \%$

$12,6 \%$

$5,5 \%$
$69,3 \%$
$2,1 \%$
$18,5 \%$
$5,0 \%$
$5,1 \%$

6, $4 \%$

$6,3 \%$

$6,3 \%$

$12,9 \%$

$68,1 \%$
$61,2 \%$

$6,2 \%$

$0,7 \%$

$30,5 \%$

$1,4 \%$
$31,7 \%$

22, $2 \%$

$33,3 \%$

$10,9 \%$

$1,9 \%$

Propriedades

\section{Físicas}

$\begin{array}{lcccccc}\text { a } & 11,620 & 11,520 & 11,603 & 11,637 & 11,528 & 11,753 \\ \mathrm{n} & 1,798 & 1,830 & 1,808 & 1,790 & 1,796 & 1,792 \\ \mathrm{D} & 4,15 & 4,22 & 4,13 & 4,07 & 3,99 & 3,886 \\ 20 & 7,75 & 8,10 & 7,90 & 7,79 & 8,13 & 7,43\end{array}$

Composição

química

$\begin{array}{lccrrrr}\mathrm{SiO}_{2} & 35,87 & 36,96 & 37,33 & 36,24 & 38,02 & 37,47 \\ \mathrm{TiO}_{2} & \text { tr } & - & 0,02 & 0,28 & 0,03 & 0,39 \\ \mathrm{Al}_{2} \mathrm{O}_{3} & 20,84 & 20,65 & 20,96 & 20,36 & 21,02 & 17,41 \\ \mathrm{Fe}_{2} \mathrm{O}_{3} & 0,06 & 0,70 & 0,68 & 1,80 & 1,98 & 7,15 \\ \mathrm{FeO} & 1,78 & 34,30 & 30,58 & 2,90 & 28,12 & 14,62 \\ \mathrm{MnO} & 38,24 & 2,45 & 2,19 & 30,45 & 0,64 & 0,88 \\ \mathrm{MgO} & 0,22 & 3,17 & 1,25 & 3,29 & 7,87 & 2,75 \\ \mathrm{CaO} & 2,72 & 1,81 & 7,05 & 4,45 & 2,25 & 19,76 \\ \mathrm{Na}_{2} \mathrm{O} & - & - & 0,03 & - & 0,11 & - \\ \mathrm{K}_{2} \mathrm{O} & \infty & - & - & - & 0,01 & - \\ \mathrm{H}_{2} \mathrm{O}^{+} & - & - & - & 0,02 & -\infty & = \\ \mathrm{H}_{2} \mathrm{O}^{-} & 0,15 & - & 0,03 & 0,02 & 0,09 & \ldots \\ \mathrm{Total}^{-} & 99,88 & 100,04 & 100,12 & 99,84 & 100,14 & 100,43\end{array}$


TABELA 6

Amostra n? 1

\section{Diagrama}

$\Delta 2 \theta-n$

Espessartita

(1) Andradita

Piropo

Almandina

(2) Grossulária Piropo

Espessartita

(3) Grossulária Andradita

(4)

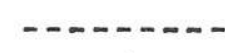

(5)

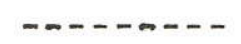

(6)

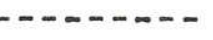

Almandina

(7) Grossulária Andradita

$62 \%$ $33 \%$
$5 \%$

Almandina

(8) Andradita Piropo

$$
\begin{array}{ll}
16 \% & \text { Almandina } \\
38 \% & \text { Andradita } \\
46 \% & \text { Piropo }
\end{array}
$$

(9)

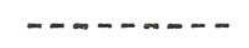

Di agrama

$\triangle 2 \theta-B$

Espessartita

$14 \%$ Andradita

$1 \%$ Piropo

$71 \%$

$4 \%$

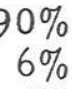

$6 \%$
$4 \%$

Espessartit

Andradita

Almandina

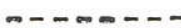

$\infty \infty-\infty \cdots$

Almandina

Grossulária

Andradita

n-mon-ma

\section{Diagrama}

$$
n-D
$$

$88 \%$

$9 \%$
$3 \%$

Espessartita $\quad 93 \%$

Andradita $2 \%$

Piropo

$92 \%$ Espessartita $93 \%$

$5 \%$ Grossulária 5\%

$3 \%$ Andradita $2 \%$

$87 \%$

$10 \%$

$3 \%$

Almandina $\quad 43 \%$

Espessartita $\quad 40 \%$ Piropo $17 \%$

Espessartita $92 \%$

Grossulária 5\% Piropo $\quad 3 \%$

$72 \%$

$9 \%$ m-n--

$19 \%$

$67 \%$

$25 \%$

$8 \%$

Espessartita $\quad 57 \%$

Almandina 29\%

Grossulária $14 \%$ 
IV - APLICAÇAO DOS NOMOGRAMAS

A aplicabilidade dos nomogramas foi comprovan da comparando-se aos resultados obtidos pelo método propos to com as composições químicas correspondentes extraídas da literatura. Os dados físicos e químicos das granadas (Deer et. al., 1962) utilizadas para a verificação do método encontram -se na Tabela 5 .

Como primeira operação foram projetados nos 30 diagramas, os dados físicos $\quad \Delta 2 \theta, \mathrm{n}$ e $\mathrm{D}$ corresponden tes a um exemplo (amostra 1), obtendo-se 15 resultados dife rentes para a composição molar, conforme Tabela 6 .

Desses resultados foram escolhidos os mais frequentes, que constam dos agrupamentos (1) e (3), cada um com três resultados, sendo selecionada a solução mais coerente quanto as porcentagens molares (agrupamento (3)).

Espessartita $90 \%$ Espessartita $92 \%$ Espessartita $93 \%$

(3) Grossulária $6 \%$ Grossulária 5\% Grossulária 5\%

Andradita $\quad 4 \%$ Andradita $\quad 3 \%$ Andradita $2 \%$

Adotou-se como composição final a média aritmé tica reajustada dos três resultados, que se mostra bastante sa tisfatória, quando comparada com os resultados da análise quí mica. 


\section{Análise física \\ (média aritmética dos \\ 3 resultados)}

\section{Análise química}

(Deer et。al。, 1962)

$\begin{array}{lcll}\text { Almandina } & \infty & \text { Almandina } & 4,0 \% \\ \text { Andradita } & 3,0 \% & \text { Andradita } & 0,2 \% \\ \text { Grossulária } & 5,3 \% & \text { Grossulária } & 7,6 \% \\ \text { Piropo } & - & \text { Piropo } & 0,9 \% \\ \text { Espessartita } & 91,7 \% & \text { Espessartita } & 87,3 \%\end{array}$

\footnotetext{
O mesmo procedimento foi adotado para
}

outros exemplos da Tabela 7 mostrando que existe uma razoável aproximação entre os resultados obtidos pelas constantes físicas e aqueles calculados pela análise química, e por con seguinte o método proposto pode substituir com vantagem o processamento laborioso da análise química.

Convém salientar que estes novos diagramas não se aplicam as espécies ricas em $\mathrm{TiO}_{2}$ (schorlomita e melanita) e, mesmo para as demais especies, poderão surgir casos em que uma análise química semi-quantitativa de um cátion característico é indispensável. Entretanto, a análise fí sica indica com grande aproximação o tipo de granada, embo m ra indicando apenas uma composição ternária os demais termos ocorrem em geral em porcentagens reduzidas não influin do na classificação da granada. 
TABELA 7

Porcentagens molares das amostras testadas

Amostra

1

Almandina

Andradita

Grossulária

Piropo

Espessartita

2

Almandina
Andradita
Grossulária
Piropo
Espessartita

3

Almandina
Andradita
Grossulária
Piropo

Espessartita

4
Análise física

\section{Análise química}
$4,0 \%$
$0,2 \%$
$7,6 \%$
$0,9 \%$

$87,3 \%$

$91,7 \%$

$67,5 \%$

$76,7 \%$

$2,1 \%$

$3,1 \%$

$9,5 \%$

$23,0 \%$

$12,6 \%$

$5,5 \%$

$\begin{array}{cr}76,7 \% & 69,3 \% \\ - & 2,1 \% \\ 22,7 \% & 18,5 \% \\ 0,6 \% & 5,0 \% \\ - & 5,1 \%\end{array}$

$10,0 \%$

$6,4 \%$

$6,3 \%$

$6,3 \%$

$18,0 \%$

$12,9 \%$

Espessartita
$68,1 \%$ 
Amostra

5

Almandina

Andradita

Grossulária

Piropo

Espessartita

6

Almandina

Andradita

Grossulária

Piropo

Espessartita

\section{Análise física}

$56,7 \%$

$5,6 \%$

-

$37,7 \%$

$-$

$33,0 \%$

$16,0 \%$

$51,0 \%$

-
Análise química

$61,2 \%$

$6,2 \%$

$0,7 \%$

$30,5 \%$

$1,4 \%$

$31,7 \%$

$22,2 \%$

$33,3 \%$

$10,9 \%$

$1,9 \%$ 
$\underline{\mathrm{V}-\mathrm{RESUMO}}$

Este trabalho procura, através de nomogramas triangulares, identificar as misturas isomorfas pertencen tes ao grupo das granadas, dando uma idéia aproximada de sua composição, sem necessidade da análise química quantita tiva. Para tanto, associa três propriedades físicas ( $\Delta 2 \theta$, n e D) à variação de composição química, sendo indispensá vel o conhecimento desses três parâmetros para a classificação do tipo de granada.

Nos nomogramas são apresentados as constan tes físicas das granadas mais frequentes na natureza (almandina, andradita, grossulária, piropo e espessartita), em relação a composição molar.

A substituição do parâmetro $a_{0}$ pela diferen ça $\Delta 2 \theta$ constitui uma grande vantagem do método, já que, a determinação das dimensões da cela unitária étrabalhosa demorada.

A construção dos nomogramas triangulares foi possível graças a comprovação de uma linearidade de $\Delta 2 \theta$ em função da variação da composição química.

Os diagramas triangulares bidimensionais faci litam o manuseio e visualização dos pontos projetados, o que não acontece às representações tetraédricas (Winchell, 1951), aplicando-se à maioria das granadas que aparecem na natureza $(83 \%)$. 
VI - AGRADECIMENTOS

O autor deseja expressar os seus agradecimentos ao orientador Prof. Dr. William Gerson Rolim de Camargo da Cadeira de Mineralogia do Instituto de Geociências da Univer sidade de São Paulo, pela dedicação e estímulo.

Aos Drs. Kenkichi Fujimori, José Vicente Vala relli e Cirano Rocha Leite, que contribuiram através de oportu nas sugestões, a srta. Vera Lucia da Costa, responsável pela dâ tilografia do texto, sinceros agradecimentos.

VII - BIBLIOGRAFIA

1 - Azároff, L. V. e Buerger, M॰J., (1958), The power method. Mc Graw-Hill Book Co。, New York.

2 - Belyankin, D.S., e Petrov, V.P., (1941), The grossularoid group (hibschite, plazolite)-Am.Mineral., vol. 26, $450-453$.

3 - Camargo, W. G. R॰, (1965), Minerais Uraníferos de Perus, S.P., (Tese de cátedra).

4 - Camargo, W.G.R。, e Svisero, D。P., (1968), Uma nova câ mara de pó para difração de raios-X - An. Acad. Brasil. Cienc. vol. $40,71-75$.

5 - Deer, W.A., Howie, R.A. e Zussman, J॰, (1962), Rock-Forming minerals, - vol. I, Ortho-and Ring silicates, Longmans, Green and Co. Ltd, London. 


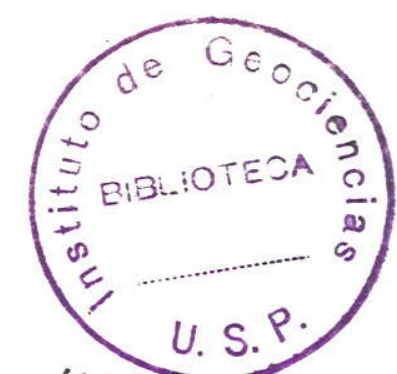

6 - Fleischer, $\mathrm{M}_{\bullet} \mathrm{H}_{\bullet}$, (1937), The relation between chemical composition and physical properties in the group - $\mathrm{Am}$. Mineral., vol. 32, 751-759.

7 - Ford, W. E., (1915), A study of the relations existing between the chemical, optical and other properties of the garnet group - Am. Jour. Sci. vol. 40, 33-49.

8 - Frondel, C., (1962), Dana's System of mineralogy, sétima edição, Silica minerals, John Wiley and Sons, Inc., New York。

9 - Gomes, C.B., Dutra, C. V., Hypolito, R。 e Valarelli, J. V. (1968), Granadas titaníferas das rochas alcalinas de Itapi rapuã, S.P. - An. Acad. Brasil. Cienc., vol. 40, 313-326.

10 - Grigoryev, D.P., (1964), Aspects of theoretical minera logy in the U.S.S.R., A collecion of papers, vol. 18, 58-75, International series of monogrphs on Earth Sciences, The Macmillan Co., New York。

11 - Kennedy, G. C., (1947), Charts for correlation of optical properties with chemical composition of some rock forming minerals - Am. Mineral., vol. 32, 561-573.

12 - Levin, S.B., (1949), The physical analysis of the polycomponent garnet Am. Mineral., vol. 34, 279.

13 - Skinner, B.J., (1956), Physical properteis of end-members of the garnet group - Am. Mineral., vol. 41, 428-436. 
14 - Sobolev, N. V., (1964), Classification of rock-forming garnets, Doklady of the Academy of Sciences U.S.S.R. Earth Science Sections, vol. 157, 79-82.

15 - Sriramadas, A., (1957), Diagrams for the correlation of unit cell edges and refractive indices with the chemical composition of garnets - Am. Mineral., vol. 42, 294-298.

16 - Subramanian, A. P॰, (1962), Petrologic Studies, A. E.J. Engel, Horold L. James e B. F. Leonard Editores, publica do por The Geological Society of America, United States of America.

17 - Troger, W.E., (1967), Optische Bestimmung der Gesteinsbildenden Minerale vol. II, E. Schweizerbart'sche Verlagsbuchhandlung, Stuttgart, Germany。

18 - Winchell, A.N. e Winchell, H. (1951), Elements of optical mineralogy, 4a. edição, part II, Descriptions of Minerals, John Wiley and Sons, Inc. New York. 